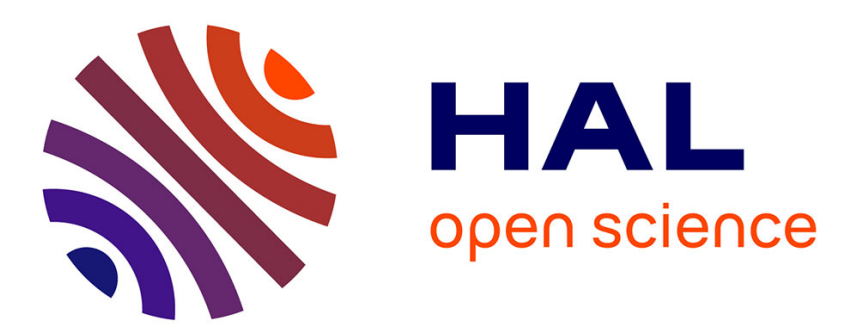

\title{
Consistent Coupled Optical and Thermal Analysis of Volumetric Solar Receivers with Honeycomb Absorbers
}

Mahmoud Mahmoud Alaa Ali, Mohamed Rady, Mohamed Attia, Emad Ewais

\section{To cite this version:}

Mahmoud Mahmoud Alaa Ali, Mohamed Rady, Mohamed Attia, Emad Ewais. Consistent Coupled Optical and Thermal Analysis of Volumetric Solar Receivers with Honeycomb Absorbers. Renewable Energy, 2019, 145, pp.1849-1861. 10.1016/j.renene.2019.07.082 . hal-02185255

\section{HAL Id: hal-02185255 https://hal.science/hal-02185255}

Submitted on 18 Aug 2019

HAL is a multi-disciplinary open access archive for the deposit and dissemination of scientific research documents, whether they are published or not. The documents may come from teaching and research institutions in France or abroad, or from public or private research centers.
L'archive ouverte pluridisciplinaire HAL, est destinée au dépôt et à la diffusion de documents scientifiques de niveau recherche, publiés ou non, émanant des établissements d'enseignement et de recherche français ou étrangers, des laboratoires publics ou privés. 


\section{Accepted Manuscript}

Consistent coupled optical and thermal analysis of volumetric solar receivers with honeycomb absorbers

Mahmoud Ali, Mohamed Rady, Mohamed A.A. Attia, Emad M.M. Ewais

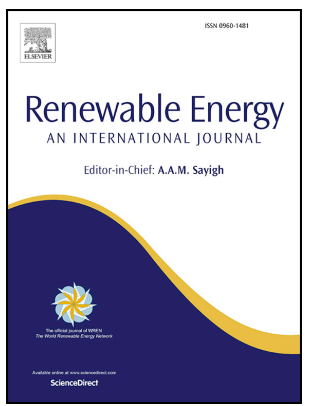

PII:

S0960-1481(19)31102-4

DOI:

https://doi.org/10.1016/j.renene.2019.07.082

Reference: RENE 11994

To appear in: Renewable Energy

Received Date: 14 May 2019

Revised Date: 9 July 2019

Accepted Date: 15 July 2019

Please cite this article as: Ali M, Rady M, Attia MAA, Ewais EMM, Consistent coupled optical and thermal analysis of volumetric solar receivers with honeycomb absorbers, Renewable Energy (2019), doi: https://doi.org/10.1016/j.renene.2019.07.082.

This is a PDF file of an unedited manuscript that has been accepted for publication. As a service to our customers we are providing this early version of the manuscript. The manuscript will undergo copyediting, typesetting, and review of the resulting proof before it is published in its final form. Please note that during the production process errors may be discovered which could affect the content, and all legal disclaimers that apply to the journal pertain. 


\section{ACCEPTED MANUSCRIPT}

1 Consistent Coupled Optical and Thermal Analysis of Volumetric Solar Receivers with Honeycomb Absorbers

a Univ. Orléans, Univ. Tours, INSA-CVL, LaMé (EA 7494), 8 rue Léonard de Vinci, 45072 Orléans, France

${ }^{b}$ Mechanical Engineering Department, Faculty of Engineering at Rabigh, King Abdulaziz University, KSA

${ }^{c}$ Mechanical Engineering Department, Faculty of Engineering at Helwan, Helwan University, 11792 Helwan, Cairo, Egypt.

${ }^{d}$ Refractory and Ceramic Materials Division, Central Metallurgical R\&D Institute (CMRDI), 11421 Helwan, Cairo, Egypt.

\section{Abstract}

In concentrating solar power plants with central towers, successful design of volumetric solar receivers requires proper understanding of the interaction between optical, heat transfer, and fluid flow phenomena occurring at the microscopic scale of receiver structure material and their effect on the overall solar to thermal efficiency. In the present article, coupled, 3D, optical, heat transfer and fluid flow numerical models have been developed for the analysis and design of honeycomb volumetric receiver modules. The optical model considers the absorptivity and micro dimensions of honeycomb absorber structure and employs a Monte Carlo ray tracing technique to calculate and analyze the absorbed solar heat flux distribution. This, in turn, is employed as a volumetric heat source term at the solid surface for consistent heat transfer and fluid flow modeling using a realistic solution domain and proper boundary conditions. The validated models have been employed to investigate the effects of different types of absorber materials, material absorptivity, and air flow rate on the performance of the solar receiver. It has been shown that positive volumetric effect and high solar-to-thermal efficiency can be obtained by controlling the absorbed radiation heat flux distribution within the honeycomb receiver using surface coating of the absorber material.

Keywords: Concentrated solar power; volumetric solar receiver; absorptivity; porous ceramics;

Monte Carlo ray tracing; CFD

* mahmoud.ali@univ-orleans.fr (Mahmoud ALI)

† mradhi@kau.edu.sa (Mohamed Rady) 
$1 \quad$ Nomenclature

A Surface area, $\mathrm{m}^{2}$

$c_{p} \quad$ Specific heat, $\mathrm{J} / \mathrm{kg} \mathrm{K}$

$d_{c h}$. Honeycomb channel diameter, $\mathrm{mm}$

$h \quad$ Heat transfer coefficient, $\mathrm{W} / \mathrm{m}^{2} \mathrm{~K}$

$K \quad$ Thermal conductivity, $\mathrm{W} / \mathrm{m} \mathrm{K}$

$L_{c h} . \quad$ Axial depth, $\mathrm{mm}$

$\dot{m} \quad$ Mass flow rate, $\mathrm{kg} / \mathrm{s}$

$\mathrm{N}_{a b s .} \quad$ Number of absorbed photons

$N_{t} \quad$ Total number of photons

PPP Power per photon, $\mathrm{W}$

$P_{\text {air }} \quad$ Rate of heat transfer to air, W

$P_{a b s} \quad$ Absorbed solar power, W

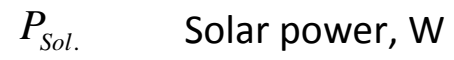

$q_{\text {Sol. }}^{\prime \prime} \quad$ Absorbed solar heat flux, $\mathrm{W} / \mathrm{m}^{2}$

Energy flux incident on the surface $k$

$q_{i n, k}$ $\left(\mathrm{W} / \mathrm{m}^{2}\right)$

$q_{\text {out }, k} \quad$ Radiative heat flux leaving surface $k\left(\mathrm{~W} / \mathrm{m}^{2}\right)$

$Q_{\text {conv }} \quad$ Convective heat losses, W

$Q_{\text {rad }} \quad$ Radiative heat losses, W

$S_{v} \quad$ Volumetric heat source, $\mathrm{W} / \mathrm{m}^{3}$

$T_{s, z \rightarrow 0} \quad$ Front wall temperature, $\mathrm{K}$

$T \quad$ Temperature, $\mathrm{K}$

$u \quad$ Air velocity, $\mathrm{m} / \mathrm{s}$

$V_{s} \quad$ Solid volume, $\mathrm{m}^{3}$

\section{Greek Symbols}

$\alpha \quad$ Absorptivity

$\beta \quad$ Incidence angle

$\varepsilon \quad$ Emissivity

$\Theta_{R} \quad$ Receiver tilt angle

$\eta_{\text {opt. }} \quad$ Optical efficiency

$\eta_{\text {Th. }}$ Thermal efficiency

$\mu \quad$ Dynamic viscosity, $\mathrm{kg} / \mathrm{m} \mathrm{s}$

$\rho \quad$ Density, $\mathrm{Kg} / \mathrm{m}^{3}$

$\sigma \quad$ Stefan-Boltzmann constant, $\mathrm{W} / \mathrm{m}^{2} \mathrm{~K}^{4}$

\section{Subscripts}

$f \quad$ Fluid

in Inlet

out Outlet

$s \quad$ Solid

$a m b$. Ambient

h heliostat 


\section{Introduction}

Concentrating Solar Power (CSP) is a promising and sustainable technology for electricity generation, chemical fuels production, solar heating and cooling, and water desalination [1-4]. Many types of CSP technologies have been utilized for electricity production such as solar tower power plants (STPPs), parabolic trough, parabolic dish, and linear Fresnel solar collectors [5]. Among the several types of CSP technologies, STPP with open volumetric solar receiver is one of the most promising technologies [6].

STPP is based on the concept of reflecting and concentrating sunlight, using sun-tracking mirrors (heliostats), on the receiver at the top of a central tower. The volumetric solar receiver (VSR) absorbs the solar radiation and converts it to high-temperature heat. Then, a heat transfer fluid (HTF) fluid flows through the receiver and removes the high-temperature heat by forced convection mechanism [7]. This heat is finally used to generate electricity using steam or gas turbine power plants [8]. Air is commonly used as a HTF due to its availability and stability.

In a typical solar tower power plant, VSR is a key element that determines the solar-tothermal efficiency of the plant. In order to reduce the thermal losses from the VSR to the environment, the outlet temperature of the HTF should be higher than the absorber frontal surface temperature indicating what is referred to in the literature as positive volumetric effect However, all VSR tested to date show high negative values of volumetric effect $[8,9]$.

Different volumetric solar receivers' designs have been investigated numerically and experimentally. They differ by the structure and the material of the receiver. Both ceramic as well as metallic materials have been tested [10-22]. Different structures include extruded honeycombs with parallel channels $[19,20]$, wire meshes [14,15], ceramic foams [23-27], and printed structures [28]. Silicon carbide (SiC) honeycomb absorber structure has been used in many STPPs such as SolAir3000 power plant [22].

\section{Literature survey}

Several numerical and experimental studies have been carried out to investigate the optical and thermal performance of VSRs using ceramic honeycombs as an absorber. Figure 1 shows the volumetric solar receiver geometry and the components of a VSR module with honeycomb absorber. Different scales of interaction between optical and thermal phenomena can be envisaged from this figure. Previous numerical studies reported in the literature employed a 
1 physical model at the channel scale and focused on analyzing the influence of channel

2 dimensions, such as channel width and wall thickness [29-32] and channel cross-section shape

3 [33] on the performance of the receiver. The important findings of these studies are

4 summarized below.

A

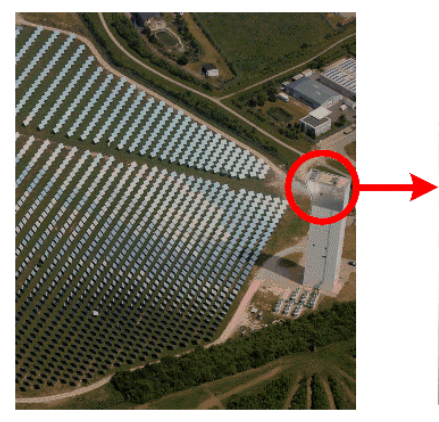

B

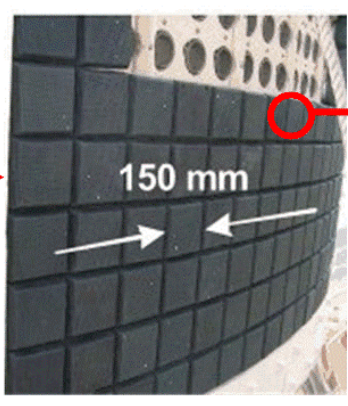

C

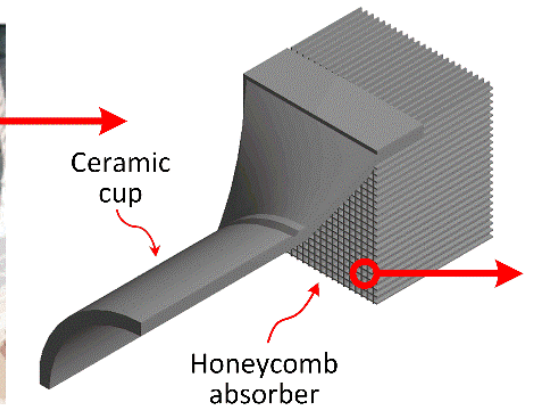

D

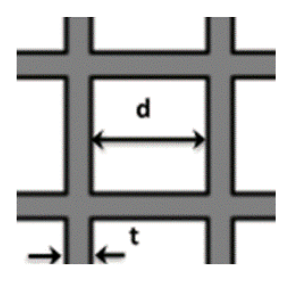

Fig. 1. Central receiver solar plant with honeycomb volumetric absorber: (A) Plant scale [30], (B) Receiver front area [30], (C) Single Module absorber and cup, (D) Channel dimensions

Fend et al. [30] carried out numerical and experimental studies to analyze the influence of channel dimensions on the thermal performance of the receiver. Two SiC honeycomb samples with different geometric parameters have been investigated. For sample 1: $d=2.18 \mathrm{~mm} \mathrm{\&} \mathrm{t}=$ $0.55 \mathrm{~mm}$ and for sample $2: \mathrm{d}=1.43 \mathrm{~mm} \mathrm{\&} \mathrm{t}=0.25 \mathrm{~mm}$. The radiative heat flux distribution on the absorber surface has been estimated using one dimensional Beer Lambert Law (BLL) and has been applied as a heat source in a CFD model using COMSOL software. Their results indicated that the sample with smaller $d$ and $t$ (sample 2) shows better performance in terms of air outlet temperature and thermal efficiency due to the increased specific surface area. However, in both cases, the air outlet temperature was less than the frontal surface temperature of the solid absorber indicating negative values of volumetric effect.

Lee et al. [29] used the 3D Monte Carlo ray tracing method (MCRT) and a 1-D CFD model to investigate the influence of channel width $(0.5-1.5 \mathrm{~mm})$, wall thickness $(0.15-0.25 \mathrm{~mm})$, and absorptivity $(\alpha=0.8,1)$ on the performance of the receiver. Their results indicate that increasing the absorptivity leads to a decrease in the reflection losses from the frontal surface of the receiver and enhance the receiver performance. In agreement with Fend et al. [30], they found that honeycomb channels with smaller channel width showed favorable performance in terms of HTF outlet temperature and thermal efficiency. However, Sanchez et al. [31] and Cagnoli et al. [32], using ray tracing code and CFD model, have shown that favorable honeycomb receiver performance has been obtained by increasing the channel width. 
It should be noted that the previous studies differ in using either simple one-dimensional

2 Beer Lambert law [30,33-35] or 3D Monte Carlo ray tracing [29,32,36] for performing the optical analysis of the receiver and estimating the radiative heat flux distribution on the absorber surface at the scale of single channel dimensions. The later represents the main heat source that may significantly affect the thermal performance of the receiver. Gomez-Garcia et al. [36] show that BLL can be used to describe the radiative heat flux distribution within the honeycomb structure near the entrance of the channel only for depths below two pitches. Moreover, BLL neglects the direction effects of the incoming solar rays as well as rays scattering inside the honeycomb channel. Therefore, using BLL may lead to improper characterization of the radiative flux distribution and overestimation of the HTF outlet temperature. Further analysis to clarify these points and in-depth analysis for the proper choice of the solution domain for consistent numerical modeling of the coupled optical and thermal phenomena inside the receiver represent one of the main objectives of the present article.

Previous studies focused on using a material with high absorptivity ( $\mathrm{SiC}$ ) to reduce the reflection losses from the frontal surface of the receiver and increase the optical efficiency [32]. Numerical studies carried out by Yilbas and Shuja [33] and Kasaeian et al. [37] indicate that cell configuration with triangular channel cross-section results in higher air outlet temperature and higher thermal efficiency and then followed by square, rectangular, hexagonal, and circular cross-sections. However, negative values of volumetric effect have been observed for all shapes of channel cross-sections evaluated. Gomez-Garcia et al. [36] performed a numerical optical study, using MCRT method, and show that an increase in the penetration depth of concentrated solar radiation can be obtained by using a novel solar receiver composed of a stack of thick square grid.

In order to achieve the required positive volumetric effect and high solar-to-thermalefficiency, radiation propagation within the honeycomb receiver should be maximized [8]. Both the architecture and the high absorptivity of $\mathrm{SiC}$ honeycombs limits radiation propagation inside the honeycomb channel. As a result, the maximum penetration depth of the absorbed heat flux is usually less than 3.3 times the channel width [29]. This leads to higher temperature at the frontal surface of the receiver, higher emission losses, lower solar-to-thermal efficiency, and lower air outlet temperature. 


\section{Outline and Contribution of Present Work}

2 The major contributions of the present article and significant differences with previous

- Consistent numerical modeling of the coupled optical and thermal phenomena inside the volumetric receiver including proper solution domain, boundary conditions, optical modelling, radiation effects, and absorbed solar radiation distribution.

- Demonstration of the basic concepts to obtain positive values of volumetric effect and high solar-to-thermal efficiency for volumetric receivers. The essential requirement is shown to increase radiation propagation within the honeycomb receiver. However, both the architecture and the high absorptivity of SiC honeycombs have been shown to limit radiation propagation inside the honeycomb channel.

- An efficient method to maximize the penetration depth within the honeycomb absorber is introduced by judicious control of the absorptivity of the honeycomb channel along its length. Of course, the solar absorptivity of the frontal surface should be as maximum as possible to reduce the reflection losses. However; the absorptivity of the internal walls can be controlled to achieve the required radiation flux distribution and obtain favorable temperature distributions. According to the author's knowledge, this method has not been yet studied in previous research work.

- A novel honeycomb receiver made of Alumina has been introduced by using judicious surface coating of the absorber material. The coating has been designed with the objective of reducing the reflection losses from the frontal surface and increasing the penetration depth of the absorbed solar heat flux inside the honeycomb receiver channel. The new introduced coated Alumina honeycomb absorbers show a favorable receiver performance in terms of air outlet temperature and solar-tothermal efficiency compared to conventional SiC honeycomb absorbers.

- The proposed method can be applied to improve the performance of honeycomb volumetric receivers.

The present article is organized as follows: section 4 describes the physical model for the optical and CFD analysis. The heat transfer and Fluid Flow Modeling are illustrated in section 5. 


\section{ACCEPTED MANUSCRIPT}

1 In section 6, the results of coupled optical and thermal models are presented and discussed.

2 Conclusions and key findings of the present study are presented in section 8.

\section{4. Physical Models for Optical and CFD Analysis}

4

5

Actually, the physical model for solar tower power plant consists of sun-tracking mirrors (heliostats) reflecting and concentrating sunlight on the receiver. However, in laboratory testing, solar furnace facilities are used to investigate the thermal and optical performance of VSRs due to high concentration ratios and high temperatures that can be achieved by these systems [38]. As shown in Fig. 2, the solar furnace used in the present study is similar to the facility used in [24] and composed of a reflector, a parabolic concentrator, and a VSR target similar to the one used in SolAir 3000. The total surface area of the reflector and the concentrator are $27 \mathrm{~m}^{2}$ and $13.5 \mathrm{~m}^{2}$, respectively. The focal distance of the concentrator is 3.8 $\mathrm{m}$. The solar furnace system redirects and focuses the incoming sunlight onto the receiver module surface. The total depth of the absorber (Z) is $50 \mathrm{~mm}$ with channels of square crosssection. The honeycomb absorber receives the radiative flux and converts it to hightemperature heat. Then, air flows through the receiver and removes the thermal energy by forced convection.

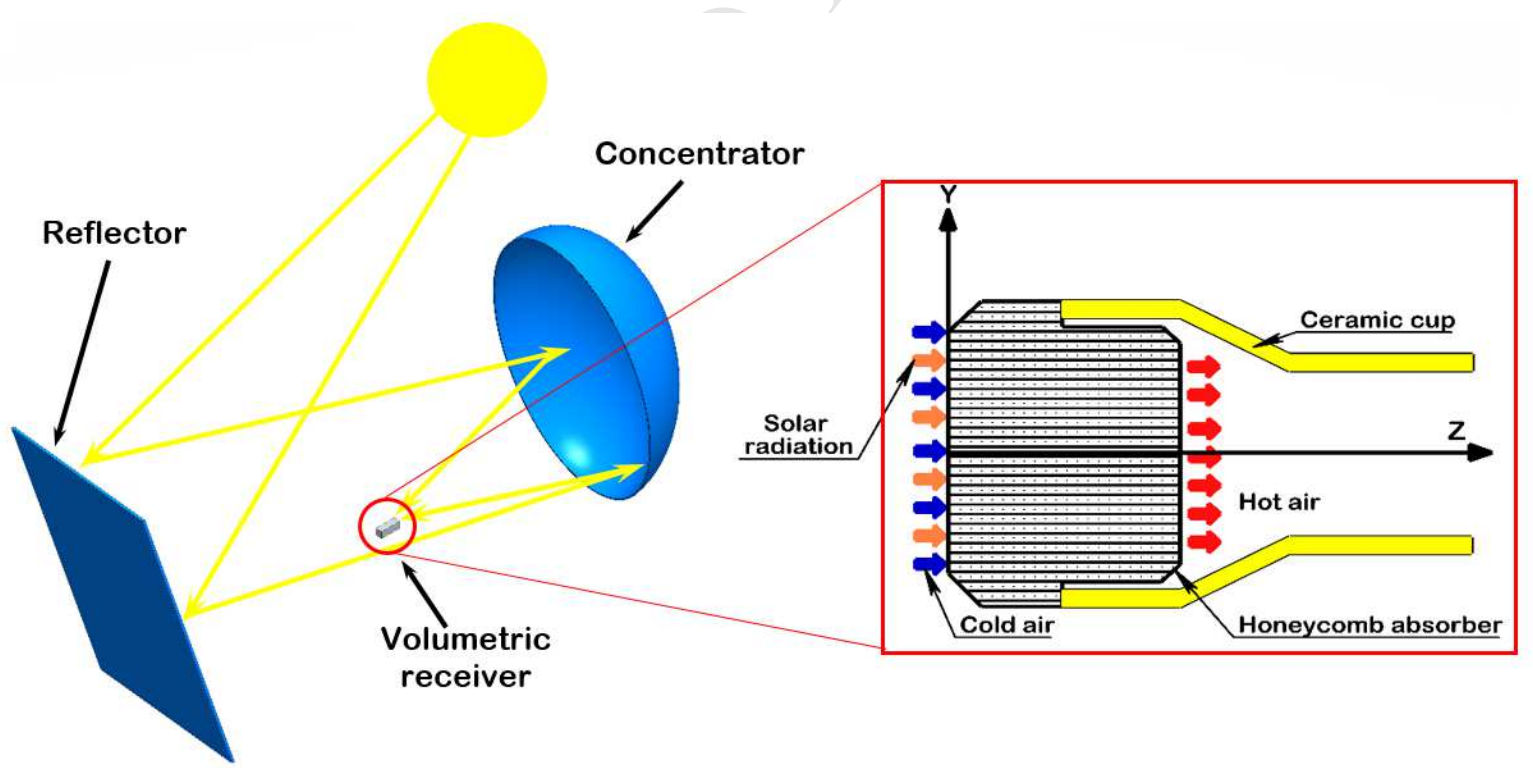

Fig. 2. Schematic diagram of the solar furnace optical model with volumetric solar receiver module.

The solar furnace optical model for the system shown in Fig. 2 has been developed using an experimentally validated object-oriented Monte Carlo based ray tracing software $\left(\right.$ Tonatiuh $^{\circledR}$ ) [39-41]. In a typical Tonatiuh ray-tracing simulation, the solar power is discretized into 
1 photons. Each photon has the same amount of energy that represents the power per photon (

$2 \quad P P P)$, which is calculated using:

3

$$
P P P=\frac{P_{\text {Sol. }}}{N_{t}}
$$

Where $P_{\text {Sol. }}$ is the solar power and $N_{t}$ is the total number of photons. The sun shape has been considered as pillbox and the value of direct normal irradiation (DNI) used in the present analysis is $1000 \mathrm{~W} / \mathrm{m}^{2}$. Since the surface area of the receiver is smaller than the solar image reflected from the concentrator, it can be assumed that the frontal surface of the receiver (A) has a constant flux distribution. The area-averaged absorbed solar heat flux $q_{\text {Sol. }}^{\prime \prime}$ that will be used as a source term for heat transfer analysis has been computed using:

$$
q_{\text {Sol. }}^{\prime \prime}=\frac{P P P \times \mathrm{N}_{a b s .}}{A}
$$

Where $\mathrm{N}_{a b s .}$ is the number of absorbed photons. A sensitivity analysis has shown that a minimum number of $10^{8}$ photons is required to reach an independent value of absorbed heat flux at the frontal area of the honeycomb receiver.

The ray-tracing algorithm is used to trace and collect the absorption and scattering data of the simulated photons through the system, starting from the light source (the sun) going towards the reflector, the concentrator and finally reaching the receiver. Ray tracing is also used for tracking the paths of the simulated photons through the receiver until they exit it or completely absorbed. This allows to determine the absorbed heat flux at each surface of the honeycomb channels (upper, lower, right, and left surfaces). Complete description of the optical model and analysis of results have been reported by the present authors elsewhere [27].

Tonatiuh has been designed to simulate either specular or diffuse surface behavior. The reflection mechanism of a real ceramic material depends on the manufacturing process. It is neither purely specular nor purely diffuse, but it is a mixture of the two. The effects of specular and diffuse reflectivity on the accuracy of the optical model have been addressed before by Cagnoli et al. [32]. The results show that the assumption of specular reflection is accurate enough to reproduce the actual receiver behavior. In the present study, specular directional reflectivity has been implemented in Tonatiuh. 


\section{ACCEPTED MANUSCRIPT}

The optical analysis showed that the absorptivity of the material plays a dominant role in determining the radiative flux distribution on the honeycomb receiver surfaces. Also, the radiative flux distribution of honeycomb absorbers is highly non-uniform with prominent peaks and surface dependent. The latter finding is very important for consistent coupling of optical and CFD models. This variation of solar heat flux distribution should be properly included in the choice of physical model for CFD analysis. In the previous numerical studies [30,35], only onequarter of the honeycomb structure cells is used as a solution domain. This choice is valid only when the absorbed heat flux distributions on all honeycomb structure surfaces are identical. Therefore, in this study, an appropriate solution domain has been used as depicted in Fig. 3. The proposed solution domain allows the authors to set the absorbed heat flux of each surface as a standalone one in consistency with the optical analysis. Further details on the governing equations of CFD analysis, boundary conditions implementations and mesh generation are outlined in Section 3.
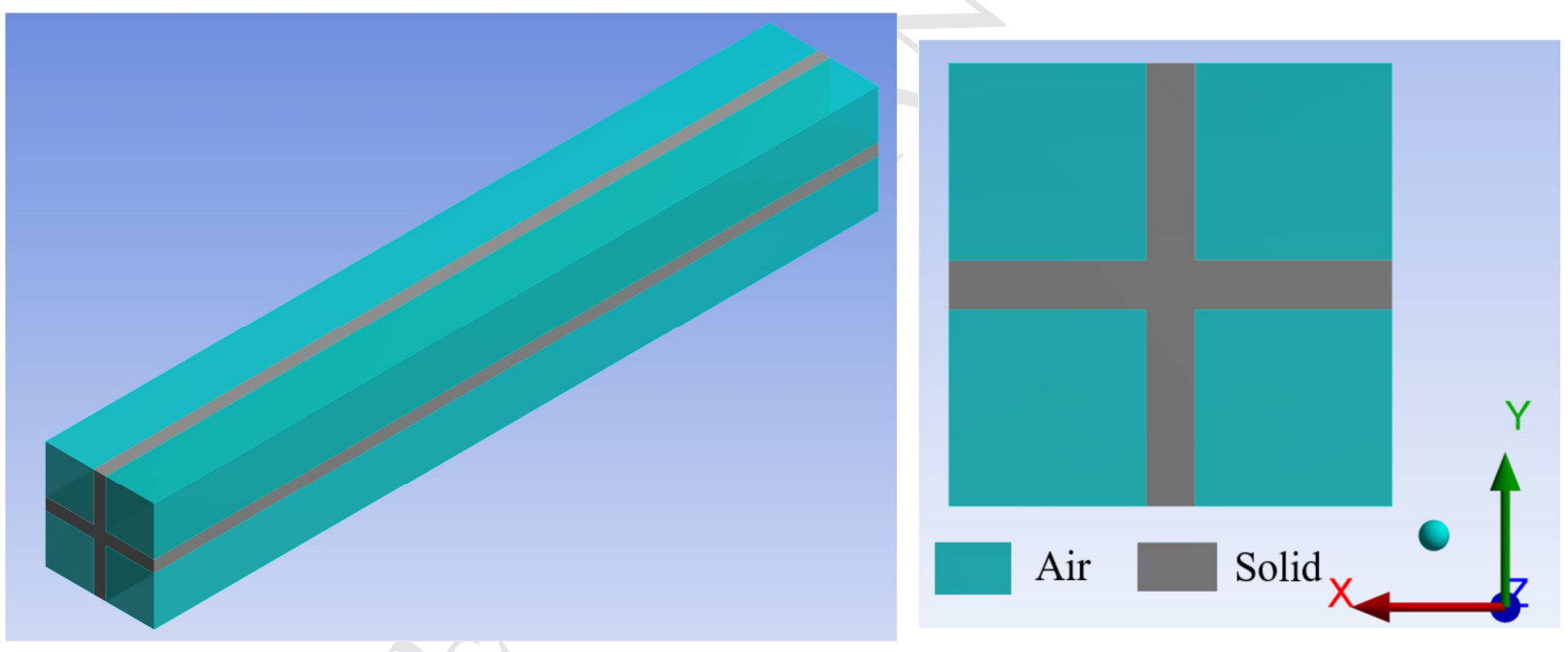

Figure 3. CFD solution domain.

\section{Heat transfer and Fluid Flow Modeling}

\subsection{Governing Equations}

The complete model of volumetric solar receiver couples the fluid dynamics and the conjugate heat transfer physics. In the present study, ANSYS ${ }^{\odot}$ software has been used for numerical modeling of the CFD phenomena inside a single channel of the numerical solution domain shown in Fig. 3. The solution domain comprising both fluid and solid domains has been discretized using ANSYS $^{\odot}$ meshing software. The grid consists of tetrahedron elements as shown in Fig. 4. In comparison with hexahedron elements, tetrahedron elements are more 
1 efficient, require less computation demand, but are more complex to generate. In addition, five

2 inflation layers placed in the fluid domain at the interface with the solid domain in order to

3 solve the boundary layer where large velocity and temperature gradients usually exist. As a

4 measure of the mesh quality, the Skewness control has been adopted. The Skewness is a

5 measure of the relative distortion of an element compared to its ideal shape and is scaled from

6 zero (Excellent) to one (unacceptable). For all meshes created in the present work, the

7 Skewness value has never exceeded 0.7 indicating a good quality mesh [44].
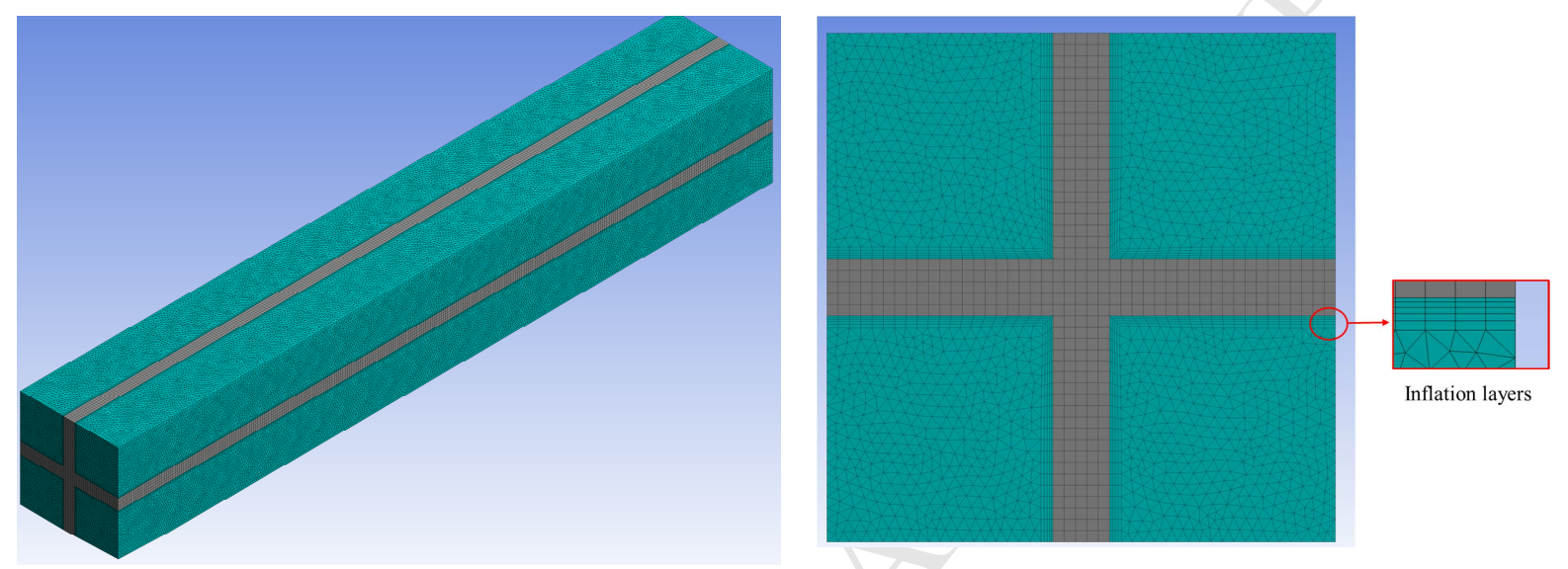

Figure 4. Numerical solution domain with generated mesh

The air flow inside the absorber channel is considered to be steady, incompressible and laminar. Under these assumptions, the 3D governing continuity, momentum, and energy equations are written as follows [42]:

$$
\frac{\partial}{\partial x_{i}}\left(\rho u_{i}\right)=0
$$

$$
\frac{\partial}{\partial x_{j}}\left(\rho u_{j} u_{i}\right)=-\frac{d p}{\partial x_{i}}+\frac{\partial}{\partial x_{j}}\left(\mu \frac{\partial u_{i}}{\partial x_{j}}\right)
$$

$$
\frac{\partial}{\partial x_{i}}\left(\rho u_{i} c_{p} T_{f}\right)=\frac{\partial}{\partial x_{i}}\left(K_{f} \frac{\partial T_{f}}{\partial x_{i}}\right)
$$

The energy equation for the solid phase is written as [42]:

$$
\frac{\partial}{\partial x_{i}}\left(K_{s} \frac{\partial T_{s}}{\partial x_{i}}\right)+S_{v}=0
$$

In the above equations, the subscript $s$ refers to the solid and $f$ refers to the fluid.

Where: 


\section{ACCEPTED MANUSCRIPT}

$\rho \quad$ Density $\left(\mathrm{Kg} / \mathrm{m}^{3}\right)$

$u \quad$ Air velocity $(\mathrm{m} / \mathrm{s})$

$\mu \quad$ Dynamic viscosity $(\mathrm{kg} / \mathrm{m} \mathrm{s})$

$T \quad$ Temperature (K)

$k \quad$ Thermal conductivity $(\mathrm{W} / \mathrm{m} \mathrm{K})$

$c_{p} \quad$ Specific heat $(\mathrm{J} / \mathrm{kg} \mathrm{K})$

$S_{v} \quad$ Volumetric heat source $\left(\mathrm{W} / \mathrm{m}^{3}\right)$

1 In the present model, energy equations for the solid and fluid phases are coupled in a 2 conjugate heat transfer problem. The radiative heat flux distribution obtained from the optical 3 simulation has been implemented as a volumetric source in the solid phase energy equation 4 using a User Defined Function (UDF). This source function represents the inter-linkage between 5 the optical and CFD models. The present volumetric source term in implemented only in the 6 surface control volumes of the solid phase. This is a well-known practice in modeling of surface 7 heat flux by an equivalent volumetric source term [43]. The solar radiation source term has 8 been calculated using:

9

$$
S_{v}=\frac{P P P \times \mathrm{N}_{a b s .}}{V_{s}}
$$

Where:

$S_{v} \quad$ Volumetric heat source $\left(\mathrm{W} / \mathrm{m}^{3}\right)$

PPP Power per photon (W)

$\mathrm{N}_{a b s .} \quad$ Number of absorbed photons (-)

$V_{s} \quad$ Volume of solid surface control-volume at the solid surface $\left(\mathrm{m}^{3}\right)$

11 The radiative heat transfer between the inner walls of the channel and between the inner 12 walls and the ambient has been taken into account using the surface to surface radiation model 13 (S2S) [44]. In the S2S radiation model, the surfaces are assumed to be gray and diffuse 14 (absorptivity is equal to the emissivity and is independent of the wavelength). Each internal 15 surface of the channel is divided into a number of discrete surfaces $(k=1$ : $N)$. Then view factors, which are a function of orientation, size and distance of the k surface, are computed

17 [44]. The radiative heat flux leaving from one surface $k$ to another surface is calculated 18 according to: 


$$
q_{o u t, k}=\varepsilon_{k} \sigma T_{k}^{4}+\left(1-\varepsilon_{k}\right) q_{i n, k}
$$

1 Where:

$$
\begin{array}{ll}
q_{\text {out }, k} & \text { Radiative heat flux leaving surface } k\left(\mathrm{~W} / \mathrm{m}^{2}\right) \\
\varepsilon_{k} & \text { Absorptivity of surface } k \\
\sigma & \text { Stefan-Boltzmann constant }\left(\mathrm{W} / \mathrm{m}^{2} \mathrm{~K}^{4}\right) \\
T_{k} & \text { Temperature of surface } k(\mathrm{~K}) \\
q_{i n, k} & \text { Energy flux incident on the surface } k\left(\mathrm{~W} / \mathrm{m}^{2}\right)
\end{array}
$$

2 In order to determine the overall performance of volumetric solar receiver, the solar to 3 thermal efficiency $\left(\eta_{S \rightarrow T h}\right)$ is calculated. The value of $\eta_{s \rightarrow T h}$. is an overall measurement that 4 indicates the ratio of thermal power gain by the fluid to the incident concentrated solar 5 radiation. The solar-to-thermal efficiency can be obtained by the following equation:

$$
\eta_{s \rightarrow T h .}=\eta_{\text {opt. }} \times \eta_{T h .}=\frac{P_{a b s}}{P_{\text {in }}} \times \frac{P_{a i r}}{P_{a b s}}=\frac{\dot{m} C_{p}\left(T_{\text {air out }}-T_{\text {air in }}\right)}{P_{\text {in }}}
$$

7 Where $\eta_{\text {opt. }}, \eta_{T h .}, P_{\text {air }}, T_{\text {air in }}$ and $T_{\text {air out }}$ are the optical efficiency, thermal efficiency, rate of heat 8 transfer to air, and air inlet and outlet temperatures, respectively.

\subsection{Boundary Conditions}

A constant velocity inlet boundary condition with a static temperature of $300 \mathrm{~K}$ has been used at the fluid domain entrance and a zero-gauge pressure outlet boundary condition has been used at the domain outlet. All contact walls between the fluid and solid domains are set to no-slip non-penetrating walls. All other surfaces have been set to symmetrical boundary conditions.

At the frontal surface of the receiver, the convection and radiation losses represent the boundary conditions for energy equation. The convection losses and radiation losses $\left(Q_{\text {conv. }}, Q_{\text {rad. }}\right)$ are expressed as:

$$
\begin{aligned}
& Q_{\text {conv. }}=h A_{s}\left(T_{s, z \rightarrow 0}-T_{a m b .}\right) \\
& Q_{\text {rad. }}=\sigma A_{s} \varepsilon\left(T_{s, z \rightarrow 0}^{4}-T_{a m b .}^{4}\right)
\end{aligned}
$$


Where:

$h \quad$ Heat transfer coefficient $\left(\mathrm{W} / \mathrm{m}^{2} \mathrm{~K}\right)$

$A_{s} \quad$ Front wall surface area $\left(\mathrm{m}^{2}\right)$

$T_{s, z \rightarrow 0} \quad$ Front wall temperature (K)

$T_{\text {amb. }} \quad$ Ambient temperature (K)

2 The heat transfer coefficient has been taken from [6] and the ambient temperature is assumed 3 to be $300 \mathrm{~K}$.

\subsection{Absorber Materials}

Ceramics are the most suitable materials for VSR due to their high operating temperature and thermal stability. In the present study, two ceramic materials have been selected and studied. These include Alumina $\left(\mathrm{Al}_{2} \mathrm{O}_{3}\right)$ and $\mathrm{SiC}$. $\mathrm{SiC}$ is widely employed in high temperature volumetric solar receiver $[45,46]$, due to its high absorptivity (about 0.8$)[47,48]$, high operating temperature and good mechanical and physical properties. Alumina has been introduced in the present study for volumetric solar receiver. Alumina is a low cost well-balanced material offering high wear resistance, high mechanical strength, and thermal stability. In addition, as compared to $\mathrm{SiC}, \mathrm{Al}_{2} \mathrm{O}_{3}$ has high oxidation resistance at high temperature. However, the solar absorptivity of $\mathrm{Al}_{2} \mathrm{O}_{3}$ is low (around 0.2) [49]. Optical analysis shall help in understanding the impact of its low absorptivity on the radiative flux distribution, the resulting optical efficiency and penetration depth of solar radiation in comparison with conventionally used materials such as SiC. Table 1 summarize the thermo-physical properties of $\mathrm{SiC}$ and $\mathrm{Al}_{2} \mathrm{O}_{3}$ used in the present study. It should be noted that Silicon Carbide and Alumina used in volumetric solar receivers and implemented in the present study are opaque materials. Pure silicon carbide is colorless and transparent. However, the production of transparent, translucent, and opaque ceramics is obtained by controlling its microstructure and inclusion of impurities during the manufacturing process $[50,51]$. The optical properties of $\mathrm{Al}_{2} \mathrm{O}_{3}$ and $\mathrm{SiC}$ used in the present study have been reported in recent references $[47-49,53]$ dealing with characterization of materials for solar receivers. The emissivity of Alumina has been reported by P. Auerkari [53]. For wavelength up to $2.5 \mu \mathrm{m}$ (wavelength of interest), the average value of emissivity is around 0.2 and it decreases with increasing the temperature. The temperature dependence of thermo-physical properties of $\mathrm{SiC}, \mathrm{Al}_{2} \mathrm{O}_{3}$ and air are taken into account as listed in table 1 . 
1 Table 1. Thermo-physical properties of $\mathrm{SiC}, \mathrm{Al}_{2} \mathrm{O}_{3}$, and air.

\begin{tabular}{|c|c|c|c|}
\hline \multicolumn{4}{|l|}{ Silicon Carbide } \\
\hline \multicolumn{2}{|l|}{ Property } & Value & Ref. \\
\hline \multicolumn{2}{|c|}{ Density $(\rho)\left(\mathrm{kg} \cdot \mathrm{m}^{-3}\right)$} & 3100 & [52] \\
\hline \multicolumn{2}{|c|}{ Thermal Conductivity $\left(K_{s}\right)\left(\mathrm{W} \cdot \mathrm{m}^{-1} \mathrm{~K}^{-1}\right)$} & $K_{s}=\frac{52000 e^{-1.24 \times 10^{-5} T}}{T+437}$ & [52] \\
\hline \multicolumn{2}{|c|}{ Specific Heat $\left(C_{p}\right)\left(\mathrm{J} \cdot \mathrm{Kg}^{-1} \cdot \mathrm{K}^{-1}\right)$} & $C_{P}=1110+0.15 T-425 e^{-0.003 T}$ & [52] \\
\hline \multicolumn{2}{|c|}{ Absorptivity $(\alpha)(-) /$ Emissivity $(\varepsilon)(-)$} & 0.8 & $\begin{array}{l}{[47,} \\
48]\end{array}$ \\
\hline \multicolumn{4}{|l|}{ Alumina } \\
\hline \multicolumn{2}{|c|}{ Density $(\rho)\left(\mathrm{kg} \cdot \mathrm{m}^{-3}\right)$} & 3750 & [53] \\
\hline \multicolumn{2}{|c|}{ Thermal Conductivity $\left(K_{s}\right)\left(\mathrm{W} \cdot \mathrm{m}^{-1} \mathrm{~K}^{-1}\right)$} & $K_{s}=-4.5536+\frac{12227}{T}$ & [54] \\
\hline \multicolumn{2}{|c|}{ Specific Heat $\left(C_{p}\right)\left(\mathrm{J} \cdot \mathrm{Kg}^{-1} \cdot \mathrm{K}^{-1}\right)$} & $C_{P}=1429.4-\frac{197620}{T}$ & [54] \\
\hline \multicolumn{2}{|c|}{ Absorptivity $(\alpha)(-) /$ Emissivity $(\varepsilon)(-)$} & 0.2 & $\begin{array}{l}{[56,} \\
49]\end{array}$ \\
\hline \multicolumn{4}{|l|}{ Air } \\
\hline $\begin{array}{l}\text { Viscosity } \\
(\mu)(\mathrm{kg} / \mathrm{m} \mathrm{s})\end{array}$ & \multicolumn{2}{|l|}{ Sutherland law } & [55] \\
\hline $\begin{array}{l}\text { Thermal } \\
\text { conductivity }\left(K_{f}\right) \\
\left(\mathrm{W} \cdot \mathrm{m}^{-1} \cdot \mathrm{K}^{-1}\right)\end{array}$ & \multicolumn{2}{|c|}{$K_{f}=1.52 \times 10^{-11} T_{f}^{3}-4.86 \times 10^{-8} T_{f}^{2}+1.02 \times 10^{-4} T_{f}-3.93 \times 10^{-3}$} & [23] \\
\hline $\begin{array}{l}\text { Specific heat } \\
\left(C_{p}\right)\left(\mathrm{J} . \mathrm{Kg}^{-1} \cdot \mathrm{K}^{-1}\right)\end{array}$ & \multicolumn{2}{|c|}{$C_{P}=1.93 \times 10^{-10} T_{f}^{4}-8 \times 10^{-7} T_{f}^{3}+1.14 \times 10^{-3} T_{f}^{2}-4.49 \times 10^{-1} T_{f}+1.06 \times 10^{3}$} & [23] \\
\hline
\end{tabular}

A commercial software ANSYS fluent ${ }^{\complement}$ has been used to solve the 3-D governing equations.

4 The SIMPLE algorithm and second-order upwind scheme have been used for pressure-velocity 5 coupling and field variables interpolation from cell centers to the faces of the control volume.

6 A grid independence study has been carried out by analyzing the air outlet temperature ( $T_{\text {airout }}$

$7 \quad$ ) and the frontal surface temperature of the absorber $\left(T_{\text {solid in }}\right)$ for different grid sizes. The 8 results are shown in table 2 . It is clear that a grid with about 2,884,612 cells is fine enough.

9 Further refinements of the grid have no effect on the results. The results have been also 10 checked as a function of the convergence criteria and independent results have been obtained 11 for a set value of $10^{-6}$ for all discrete conservation equations.

12 Table 2. Grid independence study for CFD analysis.

\begin{tabular}{lll}
\hline Grid size & $T_{\text {airout }}(\mathrm{K})$ & $T_{\text {solid in }}(\mathrm{K})$ \\
\hline
\end{tabular}




$\begin{array}{lll}601,143 & 1071.38 & 1042.65 \\ 1,242,259 & 1074.02 & 1139.12 \\ 1,802,471 & 1074.89 & 1138.82 \\ 2,884,612 & 1075.071 & 1138.40 \\ 3,142,906 & 1075.24 & 1138.38\end{array}$

In order to validate the current optical and CFD models, a comparative study has been carried out with experimental studies available in the literature. Mey-Cloutier et al. [24] reported experimental data for SiC honeycomb volumetric solar receiver. The experimental work has been carried out using solar furnace facility at PROMES-CNRS Laboratory, France. The following parameters have been collected and used as model parameters:

$\mathrm{DNI}=1000 \mathrm{~W} / \mathrm{m}^{2}$, reflector area $=27 \mathrm{~m}^{2}$, concentrator area $=13.45 \mathrm{~m}^{2}$, sample thickness $=6$ $\mathrm{cm}$, sample diameter $=5 \mathrm{~cm}$, atmospheric pressure $=84.5 \mathrm{kPa}$ and mass flow rate of air $(\dot{m})=$ $1 \mathrm{~g} / \mathrm{s}$

Table 3 shows a comparison of air outlet temperature and absorbed solar heat flux on the frontal surface predicted by the current model and experimental data of Mey-Cloutier et al. [24]. It can be observed that air outlet temperature and concentrated heat flux predicted from the present numerical model and those obtained by Mey-Cloutier et al. [24] are in a good agreement.

Table 3. Comparisons of radiative heat flux and mean air outlet temperature from the honeycomb solar receiver with the experimental data of Mey-Cloutier et al. [24].

\begin{tabular}{|l|c|c|c|}
\hline & Experimental data [24] & Simulation results & Deviation \\
\hline Concentrated solar heat flux $\left(\mathrm{kW} / \mathrm{m}^{2}\right)$ & $795 \pm 3 \%$ & 760.25 & $4.371 \%$ \\
\hline Air outlet temperature $(\mathrm{K})$ & $1170 \pm 10 \mathrm{~K}$ & 1105.27 & $5.53 \%$ \\
\hline
\end{tabular}

\section{Results and Discussions}

The previous results have demonstrated the capability of the present coupled numerical optical and CFD models for the analysis and design of volumetric solar receivers. In the next sections, the models shall be employed to investigate the effects of different types of absorber materials material absorptivity, micro dimensions of the honeycomb structure, and air flow rate on the performance of the solar receiver. Section 4.1 is devoted to the analysis of absorbed solar heat flux distribution on different surfaces of the honeycomb solar receiver as obtained from the optical modeling. Two different materials with high and low absorptivity, namely SiC and $\mathrm{Al}_{2} \mathrm{O}_{3}$ are employed. Optical analysis shall help in understanding the influence of 
absorptivity on the radiative flux distribution, the resulting optical efficiency and penetration

2 depth of solar radiation. New enhancement methods to improve the performance of honeycomb solar receivers are suggested. Sections 4.2 and 4.3 are devoted to the analysis of heat transfer and fluid flow inside the receiver and their effects on the overall receiver performance.

\subsection{Analysis of Absorbed Solar Heat Flux Distribution}

Figure 5 shows a schematic of honeycomb channel and incident solar rays. As shown in Fig.5 (a), the incidence angle of solar flux $(\beta)$ is the angle between the normal direction to the frontal surface of the receiver and the line connecting the center of the heliostat module to the aiming point. In real commercial solar thermal power plant (actual and large receiver), thousands of heliostat modules are used to concentrate the incident solar radiation on the receiver surface and one volumetric solar receiver module may receive solar rays from multiple heliostats. As a result, there will be a range of incidence angle values and a dominant value is usually used in the analysis [32,56-59]. This dominant value can be controlled by changing the tilt angle of the receiver $\left(\theta_{R}\right)$. As can be seen in Fig. $5(b)$, the value of the incidence angle $(\beta)$ should be higher than zero to ensure that incident solar rays are not parallel to the axis of the honeycomb channel and exit the receiver without being absorbed. Previous studies show that an incidence angle less than 10 degrees will enhance the radiation propagation within the honeycomb receiver, however, some rays will exit the receiver without being absorbed [32]. Nakamura et al. [58] concluded that the effect of incidence angle from $10^{\circ}$ to $45^{\circ}$ on the receiver efficiency is negligible. This can be attributed to very small values of channel height as compared to channel length. Figure 6 shows a comparison of the total absorbed solar heat flux distribution using SiC honeycomb volumetric solar receiver for two different dominant incidence angles of $15^{\circ}$ and $25^{\circ}$. It can be observed that, there is a negligible difference the distribution of total absorbed solar heat flux along the receiver channel in agreement with the conclusion of Nakamura et al. [58]. Therefore, in the present study using the optical facility shown in Fig. 2, the range of the incident angle is $0^{\circ}$ to $25.6^{\circ}$ with a dominant value of $15^{\circ}$ corresponding to a receiver tilt angle of $47^{\circ}$. These values have been kept constant for all optical analysis. 
(a)

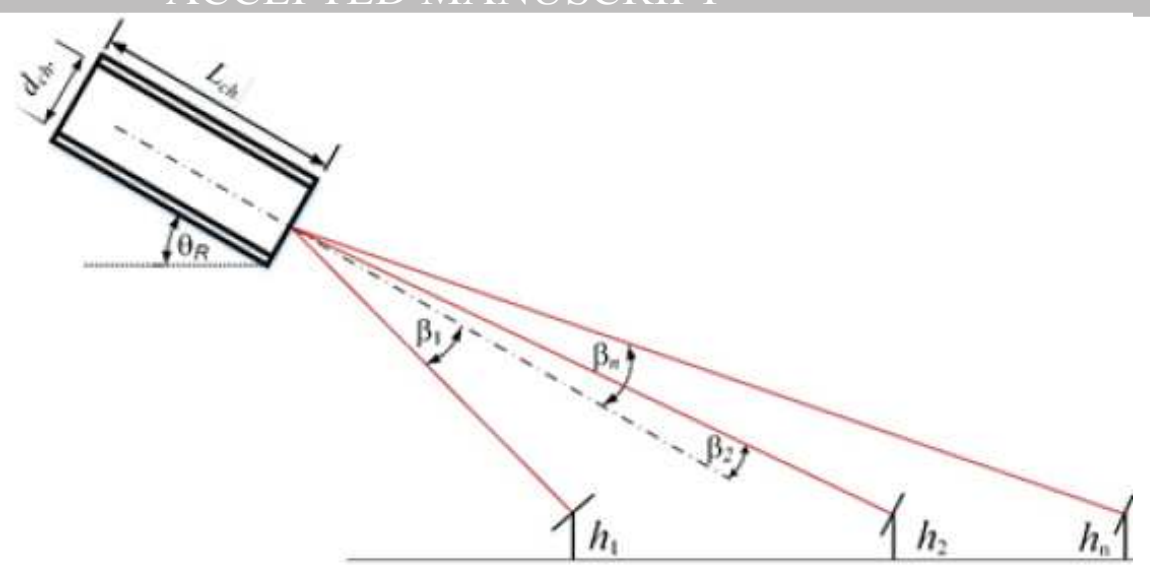

(b)

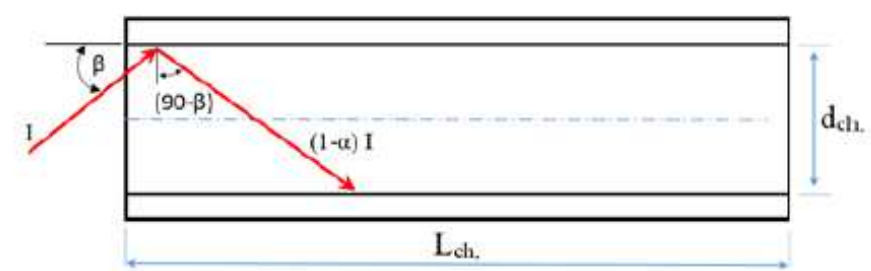

(c)

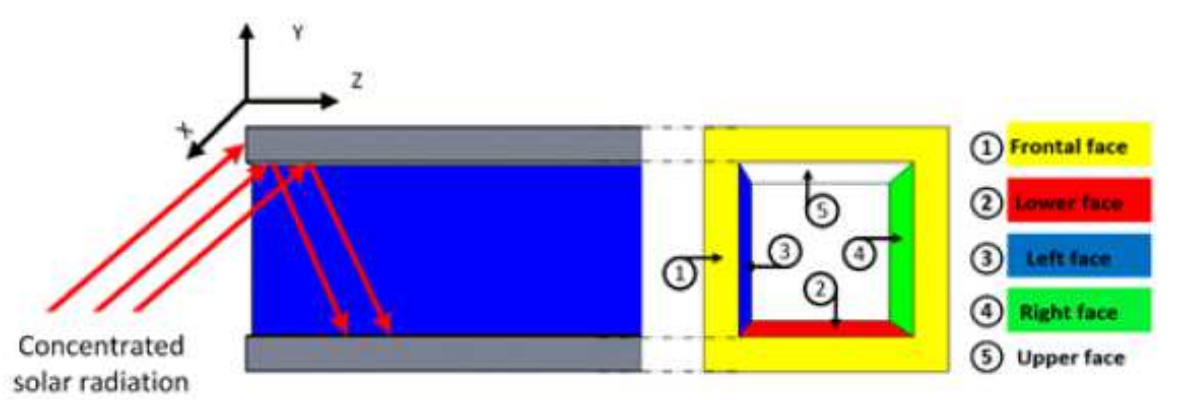

Fig. 5. Schematic of honeycomb channel and incident solar rays: (a) Solar incidence angle, (b) Incident solar ray tracing, (c) Channel surfaces

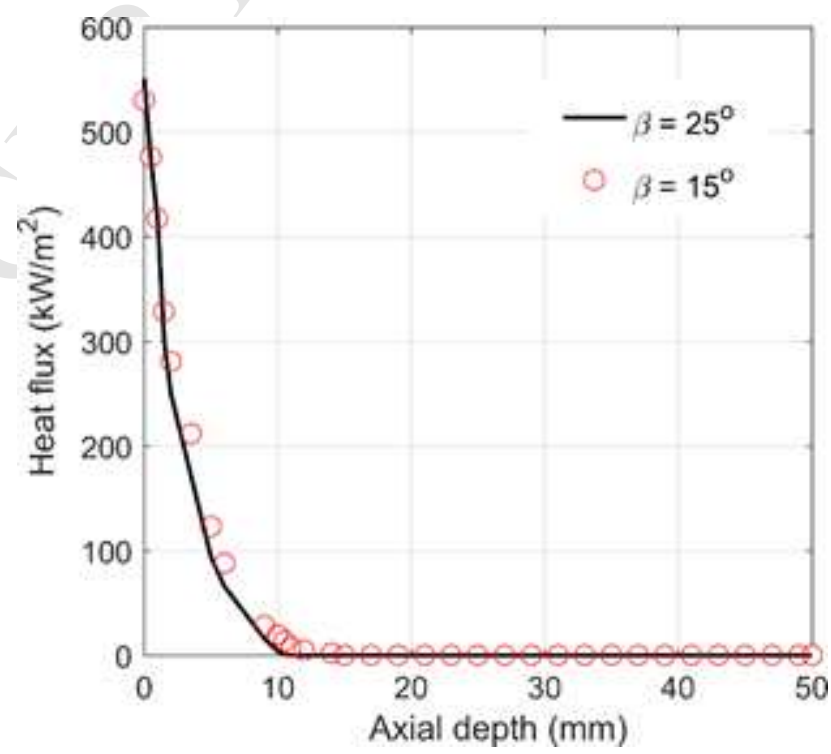

Fig. 6. Effect of incidence angle on the total absorbed solar heat flux distribution of honeycomb SiC 
It can be observed from Fig. 5(c), that most of the concentrated sunlight entering the

2 honeycomb channel firstly hit the upper surface then reflect to the other internal surfaces.

3 Therefore, the absorptivity of the upper surface plays a dominant role in determining the

4 radiative flux distribution on the honeycomb receiver internal surfaces. The absorbed heat flux

5 on the upper surface increases with the increase of surface absorptivity. Correspondingly, the values of absorbed heat flux on the other internal surfaces decrease due to the small number of reflected solar rays from the upper surface.

Figure 7 shows a detailed absorbed heat flux distribution on different surfaces of the honeycomb channel as a function of the axial depth (Z). For a higher absorptivity material (SiC of $\alpha=0.8)$, the majority of concentrated solar radiation is intercepted by the upper surface and the flux peak is located at the entrance of the Honeycomb channel $(Z=0 \mathrm{~mm})$. The reflected radiative power from the upper surface is absorbed by the lower surface. Thus, the radiative flux peak is located on deeper sections ( $Z$ around $7 \mathrm{~mm}$ ). In addition, the maximum penetration depth of the radiative flux within the honeycomb absorber is less than $10 \mathrm{~mm}$. Such a flux distribution with small penetration depth may lead to higher temperature at the frontal surface of the receiver as compared to the air outlet temperature from the receiver. This results in relatively higher values of thermal losses and lower values of solar to thermal efficiency.

In case of material with low absorptivity $\left(\mathrm{Al}_{2} \mathrm{O}_{3}\right)$, the percentage of the reflected radiative solar power from the upper surface to the lower surface is higher when compared with the percentage share of lower surface for a higher absorptivity material (SiC). However, the total absorbed radiative power by the frontal surface (see Fig. 8) and internal walls is very small compared to SiC Optical analysis shows a multi-reflection effect in the absorber channel of $\mathrm{Al}_{2} \mathrm{O}_{3}$. This results in the run-away of photons from the exit of the receiver without being absorbed. Figure 8 shows the effect of material absorptivity on the values of absorbed heat flux at the frontal surface and optical efficiency. Alumina absorbers show low values of absorbed heat flux and optical efficiency compared to SiC 


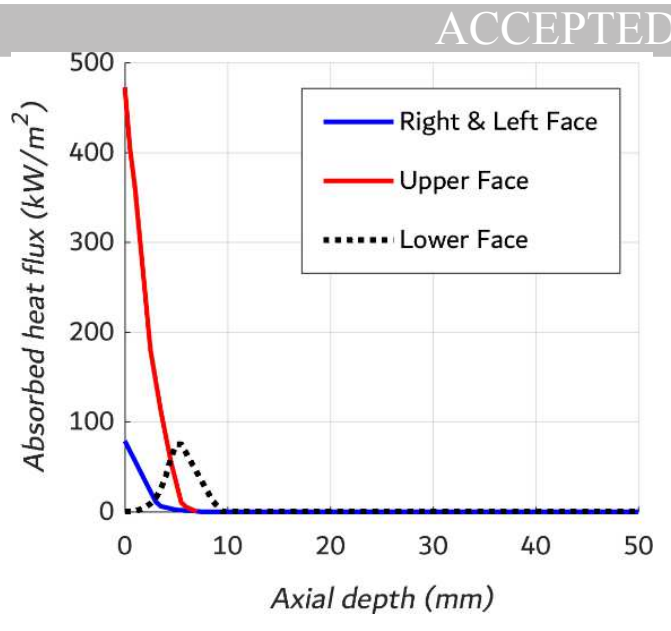

(a) $\mathrm{SiC}$

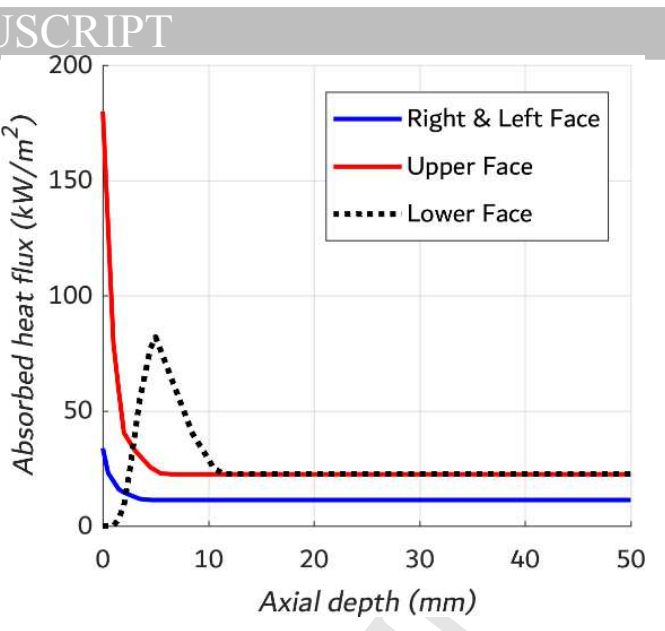

(b) $\mathrm{Al}_{2} \mathrm{O}_{3}$

Fig. 7. Absorbed solar heat flux distribution on internal surfaces of honeycomb absorber channel for: (a) $\mathrm{SiC} ;$ (b) $\mathrm{Al}_{2} \mathrm{O}_{3}$.

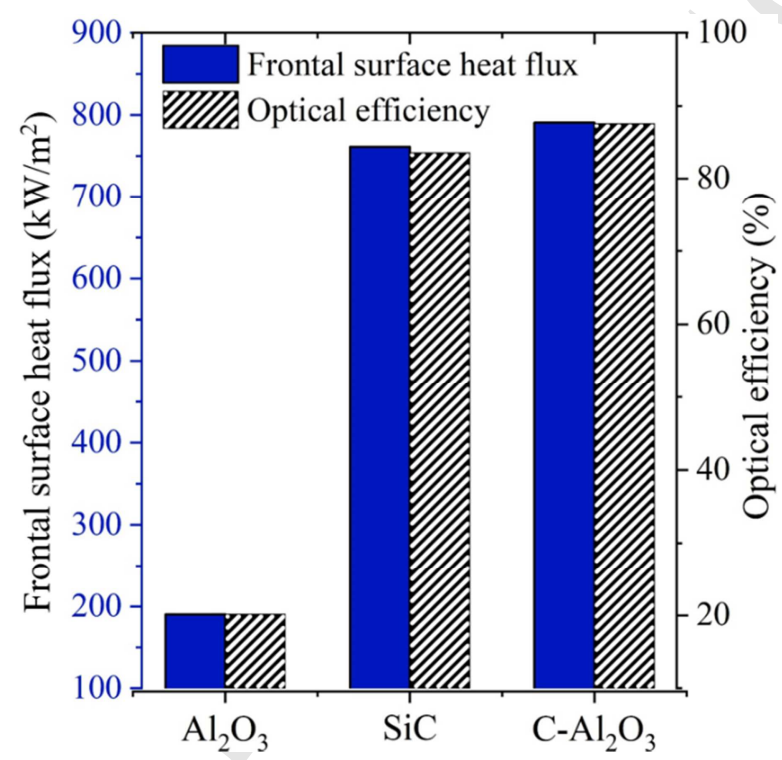

Fig.8. Effect of material absorptivity on the absorbed heat flux on frontal surface of honeycomb absorber and optical efficiency.

1 For the purpose of increasing the penetration depth of the radiative heat flux and the optical

2 efficiency of $\mathrm{Al}_{2} \mathrm{O}_{3}$ honeycomb absorber, the frontal and internal surfaces of the honeycomb

3 channel can be coated with a high absorptivity selective coating such as Pyromark $2500^{\odot}$ high-

4 temperature paint [61]. The solar absorptivity and emissivity of the coating are 0.95 and 0.9 ,

5 respectively [60]. Since most of the optical losses are due to reflection losses from the frontal

6 surface and photons escaping from the exit of the receiver, it is proposed to apply a selective

7 coating (Pyromark 2500) on the frontal surface $(Z=0 \mathrm{~mm})$ and the last $25 \mathrm{~mm}$ depth from

8 the exit ( $Z=50 \mathrm{~mm}$ ) of $\mathrm{Al}_{2} \mathrm{O}_{3}$ honeycomb absorber (see Fig. 9).

It should be noted that Pyromark 2500 high-temperature paint has been used on central receivers, including the Solar One Central Receiver Pilot Plant. As reported by the 
manufacturer, Pyromark 2500 resists temperatures up to $1093{ }^{\circ} \mathrm{C}$. Field and laboratory tests

2 indicate that the solar absorptance of the coating can decrease with time at elevated

3 temperatures, and repainting may be required every few years [60]. Pyromark 2500 was

4 implemented in the analysis performed in the present study in order to employ realistic and

5 reasonable values of solar absorptivity and emissivity of high temperature coating materials.

6 The development of solar selective coatings for high-temperature solar receivers is currently a

7 topic of research [61]. Other superior coating materials are most likely expected to be

8 produced. However, the results of the present analysis shall be applicable to other coating materials of similar values of optical properties.

Employment of the present suggested enhancement method, shows that the absorbed heat flux on the frontal surface is increased to reach a value higher than that of SiC (See Fig. 8, C$\mathrm{Al}_{2} \mathrm{O}_{3}$ ). Moreover, a maximum peak of the radiative heat flux exists in all surfaces after $25 \mathrm{~mm}$ from the entrance of the honeycomb channel (see Fig. 10). The second peak in absorbed solar flux occurs, as expected, at the beginning of the suggested coating layer. Since the optical efficiency of $\mathrm{AL}_{2} \mathrm{O}_{3}$ is below $20 \%$ as can be seen in Fig. 8 . This means that about $80 \%$ of the incident solar radiation is still available for absorption in the coated part of the channel. The absorption of this huge number of photons results in a second peak in absorbed solar heat flux that may exceed the first peak occurring at the channel inlet section. Using this technique results in preventing photons from escaping from the exit of the receiver, increasing the penetration depth of the radiative heat flux, decreasing the reflection losses from the frontal surface of the absorber and consequently increasing the optical efficiency to reach values of about $87.56 \%$.

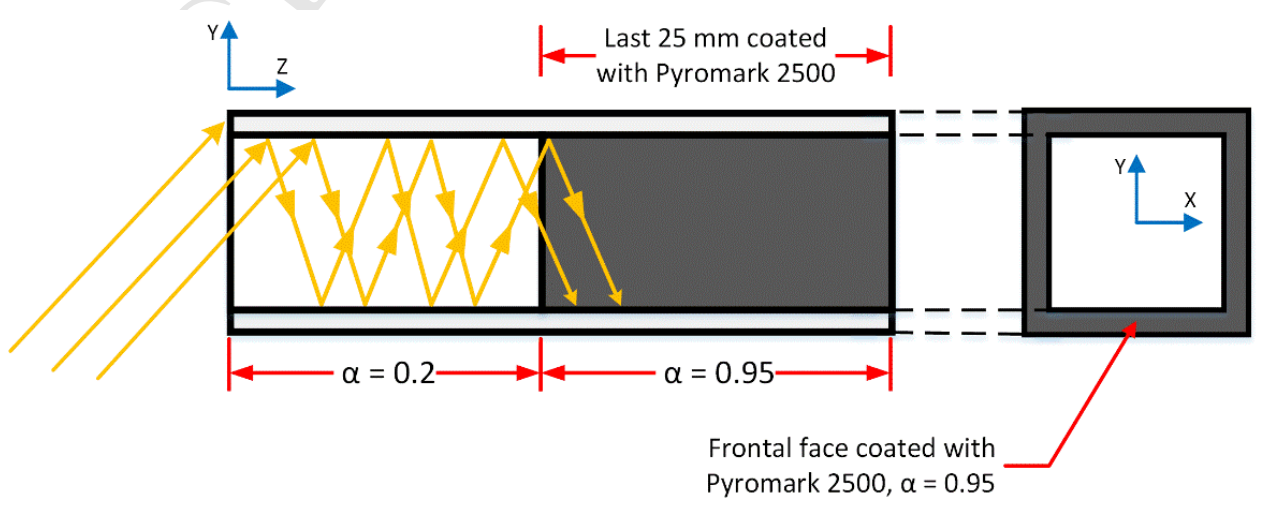

Fig.9. Schematic of present suggested enhancement method using Alumina honeycomb absorber coated with Pyromark $2500^{\circ}$. 


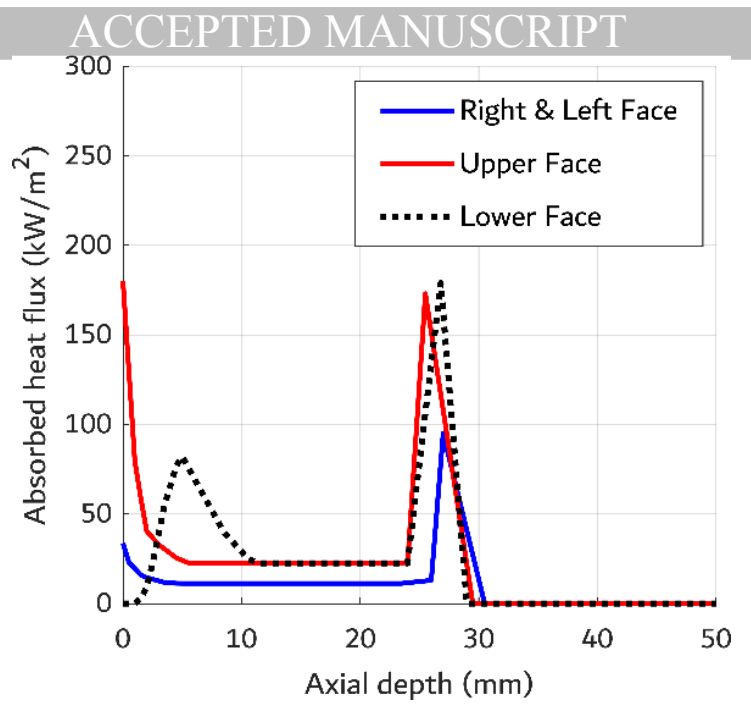

Fig. 10. Absorbed solar heat flux distribution on internal surfaces of coated alumina honeycomb absorber.

\section{$1 \quad 6.2$ Flow Fields and Temperature Distribution}

2 Numerical experiments have been carried out for honeycomb receivers for different types of

3 receiver materials. Volumetric solar receivers made from $\mathrm{SiC}$ and $\mathrm{Al}_{2} \mathrm{O}_{3}$ with selective coating

$4 \quad\left(\mathrm{C}-\mathrm{Al}_{2} \mathrm{O}_{3}\right)$ as proposed in the present study have been studied.

5 Velocity and temperature fields on the axial middle plane of SiC honeycomb absorber are 6 shown in Fig. 11. The velocity field is represented by the magnitude of velocity vectors. The 7 flow can be considered fully developed before reaching half of the channel. Air enters the 8 channel at room temperature and its temperature increases gradually until thermal equilibrium 9 between the solid phase and the fluid phase is reached.

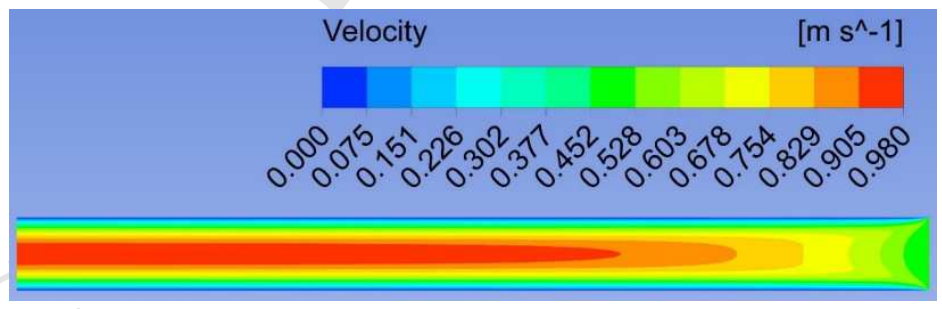

(a) Velocity field

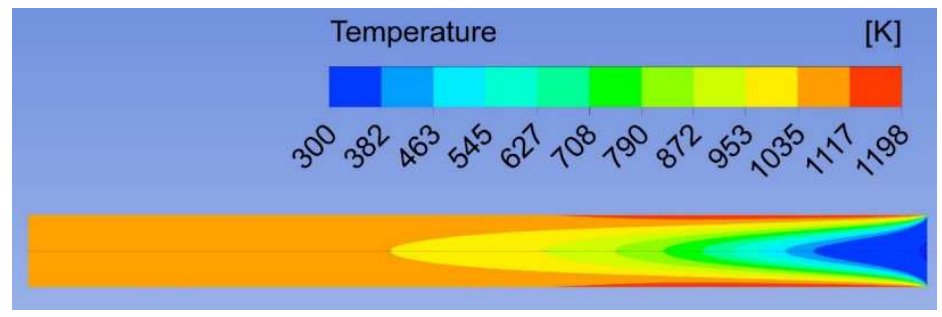

(b) Temperature field

Fig. 11. Velocity (a) and temperature fields (b) on the axial middle plane of SiC honeycomb absorber. 


\section{ACCEPTED MANUSCRIPT}

Figure 12 presents the temperature fields on the axial middle plane of $\mathrm{Al}_{2} \mathrm{O}_{3}$ and $\mathrm{C}-\mathrm{Al}_{2} \mathrm{O}_{3}$ honeycomb absorbers under the same inlet velocity $\left(u_{i n}=0.4741 \mathrm{~m} / \mathrm{s}\right)$. In case of $\mathrm{Al}_{2} \mathrm{O}_{3}$ Honeycomb absorbers, the mean air outlet temperature is very low. The flow can be considered as thermally developing till the exit of the channel. This can be attributed to lower values of optical efficiency and multi-reflection effect in the absorber channel of $\mathrm{Al}_{2} \mathrm{O}_{3}$. On the other hand, the mean air outlet temperature of $\mathrm{C}-\mathrm{Al}_{2} \mathrm{O}_{3}$ honeycomb absorbers is higher and the flow is fully developed before the exit of the channel.

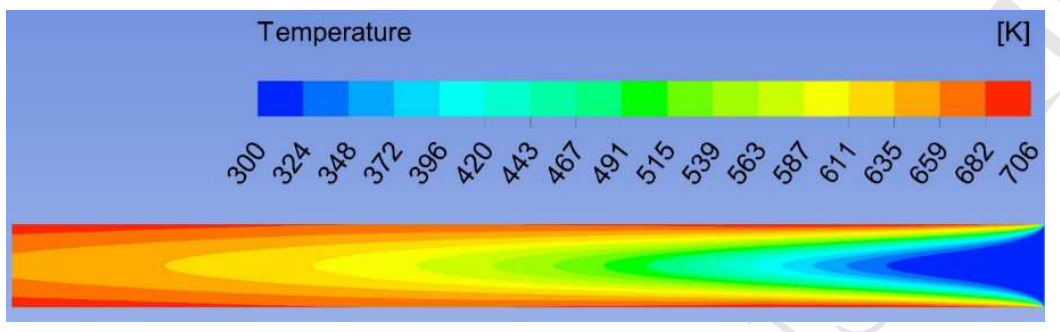

(a) $\mathrm{Al}_{2} \mathrm{O}_{3}$

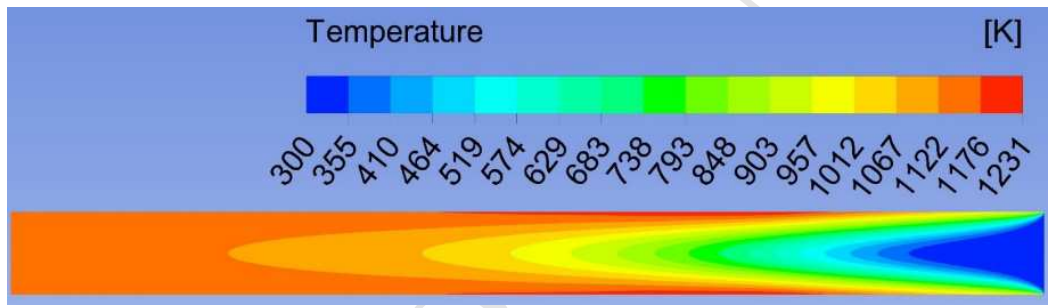

(b) $\mathrm{C}-\mathrm{Al}_{2} \mathrm{O}_{3}$

Fig. 12. Temperature field on the axial middle plane of a honeycomb absorber made of (a) $\mathrm{Al}_{2} \mathrm{O}_{3}$ and (b) $\mathrm{C}-\mathrm{Al}_{2} \mathrm{O}_{3}$.

Figure 13 depicts the mean temperature distribution of the solid and fluid phases of honeycomb structure receiver made of different materials as a function of the absorber depth using $u_{i n}=0.4741 \mathrm{~m} / \mathrm{s}$. As mentioned before, in case of honeycomb receiver made of Alumina (low absorptivity material) the majority of the concentrated sunlight on the frontal surface of the receiver is reflected back to the ambient, and the photons can run away from the exit of the receiver due to the low absorptivity of the material. Therefore, as can be seen from Fig. 13, air outlet temperature is very low (around $690 \mathrm{~K}$ ) in comparison with $\mathrm{SiC}$ and $\mathrm{C}-\mathrm{Al}_{2} \mathrm{O}_{3}$. Moreover, the solid and fluid phases do not reach the thermal equilibrium. There is a temperature difference between the two phases even at the exit of the receiver. This leads to unfavorable receiver performance in terms of air outlet temperature and thermal efficiency. On the other hand, coated alumina $\left(\mathrm{C}-\mathrm{Al}_{2} \mathrm{O}_{3}\right)$ honeycomb absorbers show favorable receiver performance in 
terms of positive volumetric effect (air outlet temperature is higher than frontal surface temperature) and relatively higher air outlet temperature as compared to $\mathrm{SiC}$ and $\mathrm{Al}_{2} \mathrm{O}_{3}$. This can be attributed to relatively higher values optical efficiency and penetration depth of the radiative heat flux. Using $\mathrm{C}-\mathrm{Al}_{2} \mathrm{O}_{3}$, penetration depth values as high as three times that of $\mathrm{SiC}$ have been obtained.

Regarding SiC honeycomb absorber (high absorptivity material), the peak temperature of the solid absorber exists near the entrance of the receiver which is higher than air outlet temperature, indicating negative value of volumetric effect and high convective and radiative heat losses. As compared to $\mathrm{C}-\mathrm{Al}_{2} \mathrm{O}_{3}$, the low performance of the $\mathrm{SiC}$ honeycomb absorber can be attributed to the absorption of the majority of the concentrated solar heat flux within the first few millimeters (10 $\mathrm{mm}$ of absorber channel). The resulting penetration depth is very small compared to coated alumina absorbers.

It should be mentioned that the solid temperature in penetration zone is governed by the thermal balance between radiative and convective losses from the frontal surface to the ambient on one side, and the convective heat transfer between the solid and fluid and heat conduction in the honeycomb absorber on the other side. For low values of penetration depth, the volumetric surface area of the honeycomb structure in the penetration zone is small. The decrease of volumetric surface area decreases the amount of convective heat removal by air. This leads to an increase in the temperature of the frontal surface and a decrease in the outlet air temperature from the receiver. Also, the increase in the frontal surface temperature is accompanied by an increase in convection and radiation losses to the ambient. Solar flux penetration inside the channel for $\mathrm{C}-\mathrm{Al}_{2} \mathrm{O}_{3}$ reaches about $30 \mathrm{~mm}$ with a peak value of 170 $\mathrm{kW} / \mathrm{m}^{2}$ as compared to about $10 \mathrm{~mm}$ with a peak value of $480 \mathrm{~kW} / \mathrm{m}^{2}$ for SiC. It can be observed that approximately all the incident solar radiation is absorbed in the first $10 \mathrm{~mm}$ of $\mathrm{SiC}$ absorber channel depth. This leads to higher temperature at the frontal surface of the receiver, higher emission losses, lower solar-to-thermal efficiency, and lower air outlet temperature. The lower front surface temperature of $\mathrm{C}-\mathrm{Al}_{2} \mathrm{O}_{3}$ is a result of the distribution of solar flux on a larger surface area as due to larger penetration depth of solar radiation. This enhances the convective heat transfer between the solid and the fluid with a remarkable decrease of solid temperature at the entrance region of the channel. The above discussion clearly demonstrate the relationship between the solar flux penetration depth and the 
1 performance of the volumetric solar receivers. Increasing the flux penetration depth has a

2 positive impact on the performance of VSR.

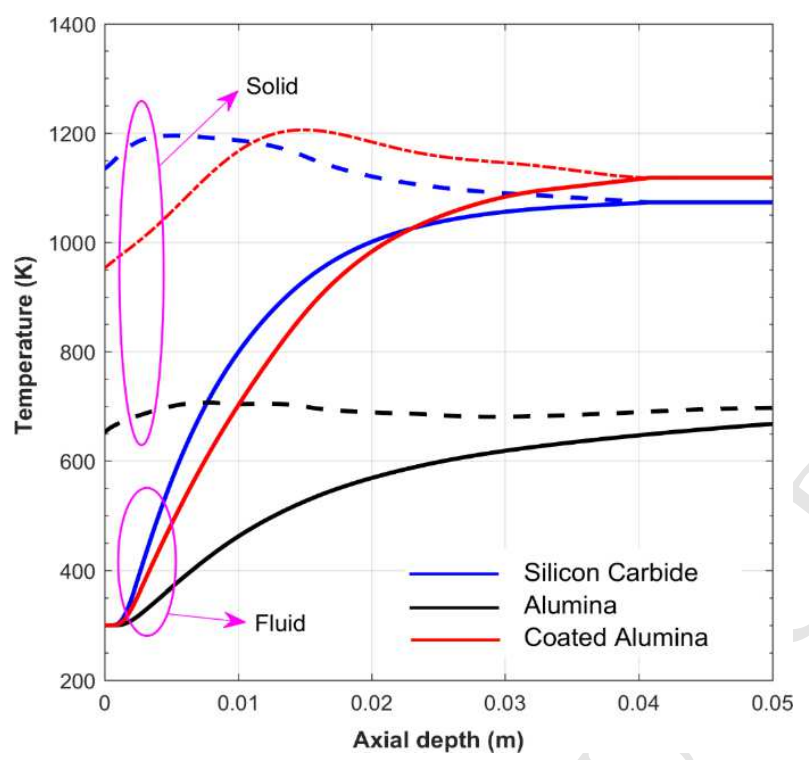

Fig.13. Temperature distribution along the centerline of a honeycomb absorber made of different materials with $\mathrm{u}_{\mathrm{in}}=0.4741 \mathrm{~m} / \mathrm{s}$.

\subsection{Evaluation of Optical and Thermal Performance of the Honeycomb Receiver}

The effects of air flow rate on the thermal performance of the solar receiver have been investigated by studying the variations of air outlet temperature $\left(T_{\text {air out }}\right)$, temperature of the absorber at the entrance $(Z=0 \mathrm{~mm})\left(T_{\text {Solid in }}\right)$, and solar-to-thermal efficiency $\left(\eta_{s \rightarrow T h .}\right)$ as a function of inlet velocity $\left(u_{\text {in }}\right)$, see Fig. 14 . Overall, it has been observed that increasing the inlet velocity of air decrease the air outlet temperature, frontal surface temperature of the receiver and increase the solar-to-thermal efficiency. This in agreement with the findings of Cagnoli et al. [32]. This may be attributed to the fact that the absorbed solar power $\left(P_{a b s}\right)$ is more or less constant since the value of the DNI and the characteristics of the solar furnace optical model are always the same. The power to air, therefore, is almost constant ( $P_{\text {air }}=\dot{m} C_{p}\left(T_{\text {air out }}-T_{\text {air in }}\right)$ ) thus, for a given value of air inlet temperature, increasing $u_{\text {in }}$ (i.e. $\dot{m}$ ) leads to a decrease in $T_{\text {air out }}$, and a decrease of the average air temperature within the honeycomb channel. This leads to a decrease in the temperature of the internal walls of the honeycomb channel as well as the frontal surface temperature. Moreover, decreasing the frontal surface temperature with the increase of $u_{i n}$ leads to a reduction in the convective and 
1 radiative heat losses $\left(Q_{\text {conv. }}\right.$ and $\left.Q_{\text {rad. }}\right)$ to the ambient. Therefore, it can be seen that the solar-

2 to-thermal efficiency of the receiver $\left(\eta_{s \rightarrow T h}\right)$ increases with the increase of $u_{i n}$.

3 For the range of $u_{i n}$ studied, both air outlet temperature and solar-to-thermal efficiency of $4 \mathrm{C}_{-} \mathrm{Al}_{2} \mathrm{O}_{3}$ honeycomb absorber proposed in the present work are higher than those of SiC and $5 \mathrm{Al}_{2} \mathrm{O}_{3}$ absorbers. This can be attributed as due to the higher penetration depth of the solar heat 6 flux and the lower convective and radiative heat losses from the frontal surface. This performance is advantageous when one considers the low cost and high-temperature oxidation resistance of $\mathrm{Al}_{2} \mathrm{O}_{3}$ as compared to conventional $\mathrm{SiC}$ honeycomb absorbers. In a first evaluation of the effectiveness of the current proposed method, the authors suggested applying high absorptivity coating at the surface of exit half of absorber channel made of low absorptivity material $\left(\mathrm{AL}_{2} \mathrm{O}_{3}\right)$. The results show an increase in the optical efficiency, penetration depth of absorber heat flux, positive volumetric effect, and high solar to thermal efficiency. Based on the present analysis, the authors believe that the suggested location of coated section should be always applied away from the channel entrance. Further parametric analysis for the optimization of this coated length shall be carried in the future.

In previous studies [30], the effects of radiative exchange between the inner walls of the honeycomb channel have been neglected. Figure 15 shows the impact of radiative emission on the solar to thermal efficiency of honeycomb structure receiver made of different materials. Overall, it has been observed that neglecting the radiative exchange will lead to overestimation of solar to thermal efficiency. The difference between $\eta_{s \rightarrow T h}$. predicted with and without considering the radiative exchange is significant especially at lower values of $u_{i n}$. This can be

22 attributed to the increase of the penetration zone temperature (see Fig. 14b) and emission loses with the decrease of $u_{i n}$. 


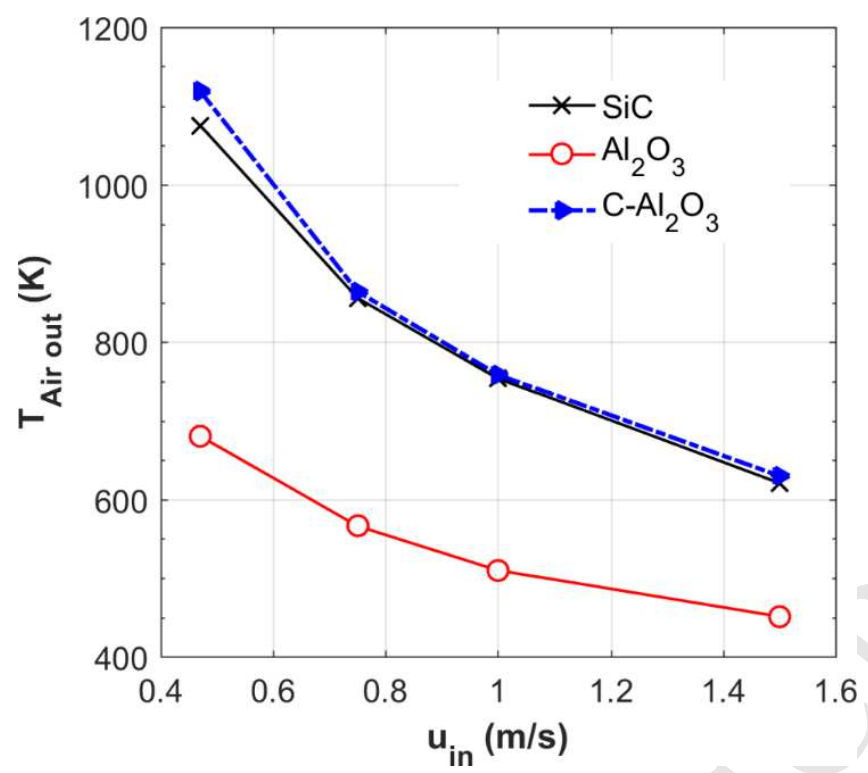

(a) Air outlet temperature

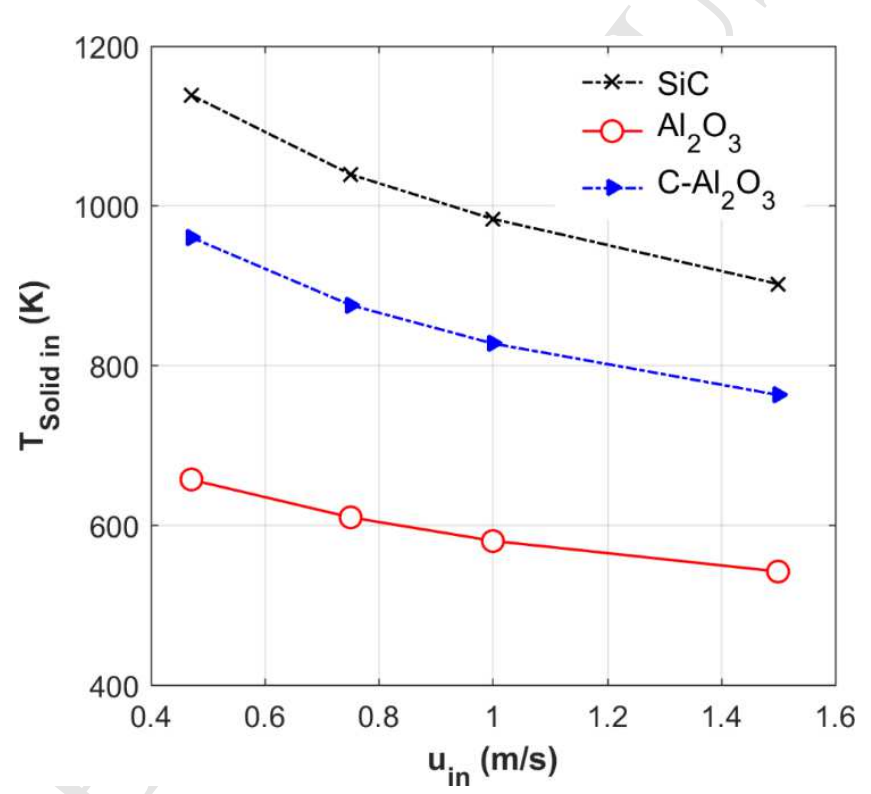

(b) Absorber frontal surface temperature 


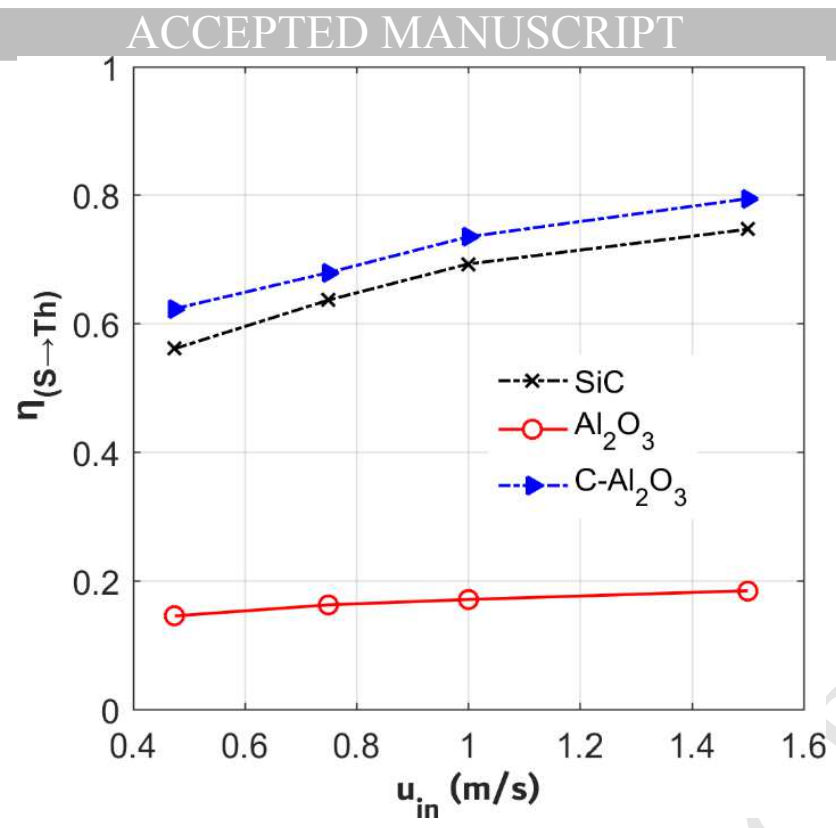

(c) Solar-to-thermal efficiency

Fig.14. Variation of: (A) air outlet temperature; (B) temperature of the absorber at the entrance; (C) solar-to-thermal efficiency with inlet velocity.

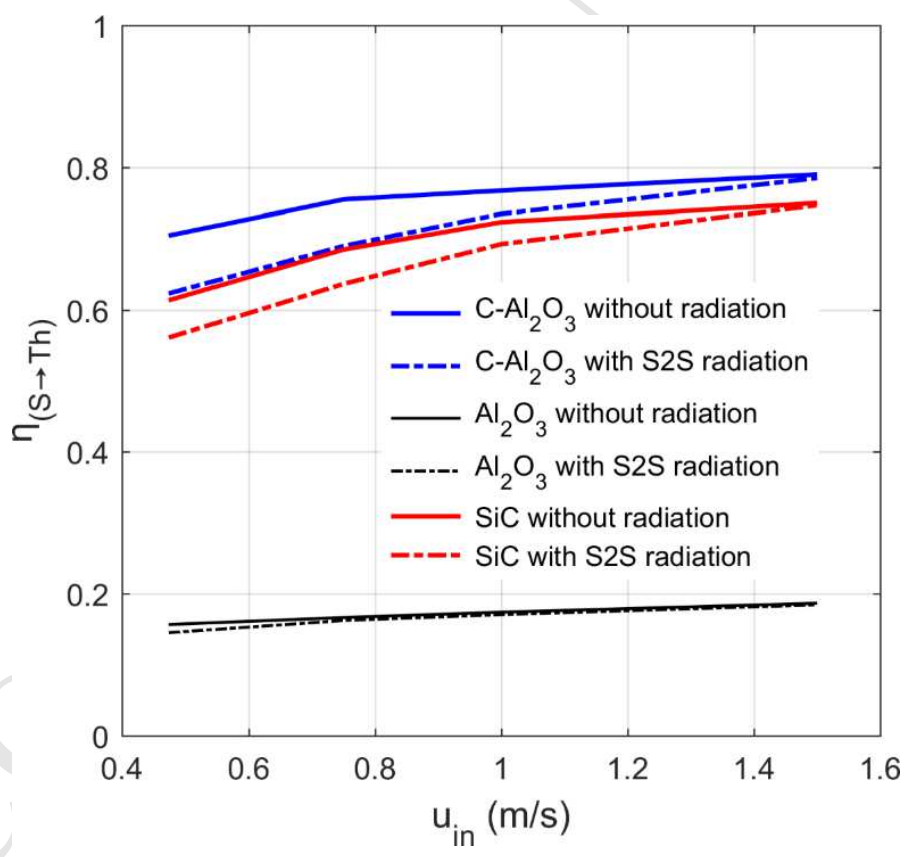

Fig. 15. Impact of radiative emission on the solar to thermal efficiency of honeycomb structure receiver made of different materials. 


\section{Conclusions}

2

Coupled, consistent, 3D, optical, heat transfer and fluid flow numerical models have been developed for the analysis and design of honeycomb volumetric solar receiver modules. The current models employ realistic physical and solution domains. They have been used to analyze the performance of solar receiver modules using Silicon Carbide and Alumina representing solar abosrbers of high and low absorbtivity, respectively.

The absorptivity of the material significantly affects the optical and thermal performance of the receiver. Positive volumetric effect and high solar-to-thermal-efficiency can be obtained by controlling the absorbed radiation heat flux distribution within the honeycomb receiver using judicious surface coating of the absorber material. A novel honeycomb receiver made of Alumina has been introduced by using judicious surface coating of the absorber material. The coating has been designed with the objective of reducing the reflection losses from the frontal surface and increasing the penetration depth of the solar flux inside the honeycomb receiver channel. The new introduced coated Alumina honeycomb absorbers show a favorable receiver performance in terms of air outlet temperature and solar-to-thermal efficiency compared to conventional SiC honeycomb absorbers.

Alumina is a low cost well-balanced material featuring high wear resistance, high mechanical strength, and thermal stability. In addition, as compared to SiC, Alumina has high oxidation resistance at high temperature. The low performance of the SiC honeycomb absorber can be attributed to that the majority of the concentrated solar heat flux is absorbed within the first few millimeters $(10 \mathrm{~mm})$ and the penetration depth is very small compared to coated Alumina absorbers. For the range of air flow velocity studied, the solar-to-thermal efficiency increases with the increase of air mass flow rate. However, this is accompanied by a decrease in the air outlet temperature and frontal surface temperature. The decrease in air outlet temperature may have a negative effect on the thermal efficiency of the power block connected to the solar receiver. 


\section{References}

[1] O. Behar, A. Khellaf, K. Mohammedi, A review of studies on central receiver solar thermal power plants, Renewable and Sustainable Energy Reviews. 23 (2013) 12-39. doi:10.1016/j.rser.2013.02.017.

[2] J. Blanco, S. Malato, P. Fernández-Ibañez, D. Alarcón, W. Gernjak, M. Maldonado, Review of feasible solar energy applications to water processes, Renewable and Sustainable Energy Reviews. 13 (2009) 1437-1445. doi:10.1016/j.rser.2008.08.016.

[3] J.M. Gordon, K.C. Ng, High-efficiency solar cooling, Solar Energy. 68 (2000) 23-31. doi:10.1016/S0038-092X(99)00053-5.

[4] T. Nakamura, Hydrogen production from water utilizing solar heat at high temperatures, Solar Energy. 19 (1977) 467-475. doi:10.1016/0038-092X(77)90102-5.

[5] D. Barlev, R. Vidu, P. Stroeve, Innovation in concentrated solar power, Solar Energy Materials and Solar Cells. 95 (2011) 2703-2725. doi:10.1016/j.solmat.2011.05.020.

[6] C.K. Ho, B.D. Iverson, Review of high-temperature central receiver designs for concentrating solar power, Renewable and Sustainable Energy Reviews. 29 (2014) 835846. doi:10.1016/j.rser.2013.08.099.

[7] A.L. Avila-Marin, Volumetric receivers in solar thermal power plants with central receiver system technology: a review, Solar Energy. 85 (2011) 891-910. doi:10.1016/j.solener.2011.02.002.

[8] A. Kribus, Y. Gray, M. Grijnevich, G. Mittelman, S. Mey-Cloutier, C. Caliot, The promise and challenge of solar volumetric absorbers, Solar Energy. 110 (2014) 463-481. doi:10.1016/j.solener.2014.09.035.

[9] M. Romero, R. Buck, J.E. Pacheco, An update on solar central receiver systems, projects, and technologies, Journal of Solar Energy Engineering. 124 (2002) 98-108. doi:10.1115/1.1467921.

[10] H. Fricker, Proposal for a novel type of solar gas receiver, in: Proceedings of the International Seminar on Solar Thermal Heat Production, Stuttgart, German Aerospace Center (DLR), Pfaffenwaldring, 1983: pp. 38-40.

[11] P. Heinrich, G. Keintzel, C. Streuber, Technology Program Solar Air Receiver-2.5 MWt System Test on Volumetric Air Receiver Technology, in: Proceedings of the 6th International Symposium on Solar Thermal Concentrating Technologies, 1992: pp. 247261.

[12] T. Hellmuth, L. Matthews, J. Chavez, C. Hale, Performance of a wire mesh solar volumetric air receiver, Solar Engineering. (1994) 573-573.

[13] R. Pitz-Paal, Evaluation of the CATREC II Receiver Test, SolarPACES Technical Report. (1996).

[14] T. Hellmuth, L. Matthews, Modeling and optimum design of a wire mesh solar volumetric air receiver, Journal of Solar Energy Engineering. 119 (1997) 208-213. doi:10.1115/1.2888020.

[15] F. Tellez, M. Romero, M. Marcos, Design of" SIREC-1" Wire Mesh Open Volumetric Solar Receiver Prototype, Solar Engineering. (2001) 357-364.

[16] J.M. Chavez, C. Chaza, Testing of a porous ceramic absorber for a volumetric air receiver, Solar Energy Materials. 24 (1991) 172-181. doi:10.1016/0165-1633(91)90057-R.

[17] R. Pitz-Paal, J. Morhenne, M. Fiebig, A new concept of a selective solar receiver for high temperature applications, Solar Energy Materials. 24 (1991) 293-306. doi:10.1016/01651633(91)90070-2. 
[18] F. Reale, G. Ruocco, A. Carotenuto, U. Nocera, F. Bonomo, Final design of a multi cavity volumetric solar receiver, Solar Energy Materials. 24 (1991) 284-292. doi:10.1016/01651633(91)90069-W.

[19] B. Hoffschmidt, The development strategy of the HiTREC volumetric receiver technology up scaling from $200 \mathrm{~kW}$ h via $3 \mathrm{MW}$ h up to $10 \mathrm{MWel}$, Proceedings of the 11th SolarPACES International Symposium on Concentrated Solar Power and Chemical Energy, Technologies, Zurich, Switzerland. (2002).

[20] B. Hoffschmidt, F.M. Téllez, A. Valverde, J. Fernández, V. Fernández, Performance evaluation of the 200-kWth HiTRec-II open volumetric air receiver, Journal of Solar Energy Engineering. 125 (2003) 87-94. doi:10.1115/1.1530627.

[21] B. Hoffschmidt, G. Dibowski, M. Beuter, V. Fernandez, F. Téllez, P. Stobbe, Test results of a $3 \mathrm{MW}$ solar open volumetric receiver, (2003).

[22] F. Tellez, M. Romero, P. Heller, A. Valverde, G. Dibowski, S. Ulmer, Thermal performance of SolAir $3000 \mathrm{~kW}$ th ceramic volumetric solar receiver, in: 12th International Symposium Solar Power and Chemical Energy Systems, October 6-8, 2004, Oaxaca, Mexico, Instituo de Investigaciones Electricas, 2004.

[23] Z. Wu, C. Caliot, G. Flamant, Z. Wang, Coupled radiation and flow modeling in ceramic foam volumetric solar air receivers, Solar Energy. 85 (2011) 2374-2385. doi:10.1016/j.solener.2011.06.030.

[24] S. Mey-Cloutier, C. Caliot, A. Kribus, Y. Gray, G. Flamant, Experimental study of ceramic foams used as high temperature volumetric solar absorber, Solar Energy. 136 (2016) 226235. doi:10.1016/j.solener.2016.06.066.

[25] F. Zaversky, L. Aldaz, M. Sánchez, A.L. Ávila-Marín, M.I. Roldán, J. Fernández-Reche, A. Füssel, W. Beckert, J. Adler, Numerical and experimental evaluation and optimization of ceramic foam as solar absorber-Single-layer vs multi-layer configurations, Applied Energy. 210 (2018) 351-375. doi:10.1016/j.apenergy.2017.11.003.

[26] F. Wang, Y. Shuai, H. Tan, C. Yu, Thermal performance analysis of porous media receiver with concentrated solar irradiation, International Journal of Heat and Mass Transfer. 62 (2013) 247-254. doi:10.1016/j.ijheatmasstransfer.2013.03.003.

[27] M. Alaa, M. Rady, M. Attia, E. Ewais, Optical study of using ceramic foams for volumetric solar receivers, in: Renewable and Sustainable Energy Conference (IRSEC), 2016 International, IEEE, 2016: pp. 284-289. doi:10.1109/IRSEC.2016.7983917.

[28] R. Capuano, T. Fend, H. Stadler, B. Hoffschmidt, R. Pitz-Paal, Optimized volumetric solar receiver: Thermal performance prediction and experimental validation, Renewable Energy. 114 (2017) 556-566. doi:10.1016/j.renene.2017.07.071.

[29] H.-J. Lee, J.-K. Kim, S.-N. Lee, Y.-H. Kang, Consistent heat transfer analysis for performance evaluation of multichannel solar absorbers, Solar Energy. 86 (2012) 1576-1585. doi:10.1016/j.solener.2012.02.020.

[30] T. Fend, P. Schwarzbözl, O. Smirnova, D. Schöllgen, C. Jakob, Numerical investigation of flow and heat transfer in a volumetric solar receiver, Renewable Energy. 60 (2013) 655661. doi:10.1016/j.renene.2013.06.001.

[31] M. Sanchez, M. Marcos, M. Romero, C. Estrada, Design Parameters Influence on Flux Distribution Through Prismatic Channels of Volumetric Absorbers, in: EuroSun2004, Conference Proceedings, 2004: pp. 953-962.

[32] M. Cagnoli, L. Savoldi, R. Zanino, F. Zaversky, Coupled optical and CFD parametric analysis of an open volumetric air receiver of honeycomb type for central tower CSP plants, Solar Energy. 155 (2017) 523-536. doi:10.1016/j.solener.2017.06.038. 
[33] B. Yilbas, S. Shuja, A Solar Volumetric Receiver: Influence of Absorbing Cells Configuration on Device Thermal Performance, International Journal of Thermophysics. 38 (2017) 1. doi:10.1007/s10765-016-2132-3.

[34] O. Smirnova, T. Fend, R. Capuano, G. Feckler, P. Schwarzbözl, F. Sutter, Determination of critical thermal loads in ceramic high concentration solar receivers, Solar Energy Materials and Solar Cells. 176 (2018) 196-203. doi:10.1016/j.solmat.2017.11.033.

[35] R. Capuano, T. Fend, P. Schwarzbözl, O. Smirnova, H. Stadler, B. Hoffschmidt, R. Pitz-Paal, Numerical models of advanced ceramic absorbers for volumetric solar receivers, Renewable and Sustainable Energy Reviews. 58 (2016) 656-665. doi:10.1016/j.rser.2015.12.068.

[36] F. Gomez-Garcia, J. Gonzalez-Aguilar, S. Tamayo-Pacheco, G. Olalde, M. Romero, Numerical analysis of radiation propagation in a multi-layer volumetric solar absorber composed of a stack of square grids, Solar Energy. 121 (2015) 94-102. doi:10.1016/j.solener.2015.04.047.

[37] A. Kasaeian, H. Barghamadi, F. Pourfayaz, Performance comparison between the geometry models of multi-channel absorbers in solar volumetric receivers, Renewable Energy. 105 (2017) 1-12. doi:10.1016/j.renene.2016.12.038.

[38] G. Levêque, R. Bader, W. Lipiński, S. Haussener, High-flux optical systems for solar thermochemistry, Solar Energy. (2017). doi:10.1016/j.solener.2017.07.046.

[39] M.J. Blanco, J.M. Amieva, A. Mancillas, The Tonatiuh Software Development Project: An open source approach to the simulation of solar concentrating systems, in: ASME 2005 International Mechanical Engineering Congress and Exposition, American Society of Mechanical Engineers, 2005: pp. 157-164. doi:10.1115/IMECE2005-81859.

[40] M. Blanco, A. Mutuberria, D. Martinez, Experimental validation of Tonatiuh using the Plataforma Solar de Almería secondary concentrator test campaign data, in: 16th Annual SolarPACES Symposium, 2010.

[41] A. Mutuberria, A. Monreal, A. Albert, M. Blanco, Results of the empirical validation of Tonatiuh at Mini-Pegase CNRS-PROMES facility, in: Proceedings of the 17th SolarPACES Int. Symposium on Concentrating Solar Power and Chemical Energy, 2011.

[42] R.H. Pletcher, J.C. Tannehill, D. Anderson, Computational fluid mechanics and heat transfer, CRC Press, 2012.

[43] S. Patankar, Numerical heat transfer and fluid flow, CRC press, 1980.

[44] A. Fluent, ANSYS fluent theory guide 15.0, ANSYS, Canonsburg, PA. (2013).

[45] T. Fend, O. Reutter, J. Bauer, B. Hoffschmidt, Two novel high-porosity materials as volumetric receivers for concentrated solar radiation, Solar Energy Materials and Solar Cells. 84 (2004) 291-304. doi:10.1016/j.solmat.2004.01.039.

[46] C.C. Agrafiotis, I. Mavroidis, A.G. Konstandopoulos, B. Hoffschmidt, P. Stobbe, M. Romero, V. Fernandez-Quero, Evaluation of porous silicon carbide monolithic honeycombs as volumetric receivers/collectors of concentrated solar radiation, Solar Energy Materials and Solar Cells. 91 (2007) 474-488. doi:10.1016/j.solmat.2006.10.021.

[47] D. Sciti, L. Silvestroni, L. Mercatelli, J.-L. Sans, E. Sani, Suitability of ultra-refractory diboride ceramics as absorbers for solar energy applications, Solar Energy Materials and Solar Cells. 109 (2013) 8-16. doi:10.1016/j.solmat.2012.10.004.

[48] D. Sciti, L. Silvestroni, J.-L. Sans, L. Mercatelli, M. Meucci, E. Sani, Tantalum diboride-based ceramics for bulk solar absorbers, Solar Energy Materials and Solar Cells. 130 (2014) 208216. doi:10.1016/j.solmat.2014.07.012. 


\section{ACCEPTED MANUSCRIPT}

[49] E. Sani, L. Mercatelli, J.-L. Sans, D. Sciti, Optical properties of black and white ZrO2 for solar receiver applications, Solar Energy Materials and Solar Cells. 140 (2015) 477-482. doi:10.1016/j.solmat.2015.02.007.

[50] Y. Kim, A. Zangvil, J.S. Goela, R.L. Taylor, Microstructure comparison of transparent and opaque CVD SiC, Journal of the American Ceramic Society. 78 (1995) 1571-1579. doi:10.1111/j.1151-2916.1995.tb08853.x.

[51] B.-N. Kim, K. Hiraga, K. Morita, H. Yoshida, T. Miyazaki, Y. Kagawa, Microstructure and optical properties of transparent alumina, Acta Materialia. 57 (2009) 1319-1326.

[52] R. Munro, Material properties of a sintered $\alpha$-SiC, Journal of Physical and Chemical Reference Data. 26 (1997) 1195-1203. doi:10.1063/1.556000.

[53] P. Auerkari, Mechanical and physical properties of engineering alumina ceramics, Technical Research Centre of Finland Espoo, 1996.

[54] T.K. Papathanasiou, F. Dal Corso, A. Piccolroaz, Thermo-mechanical response FEM simulation of ceramic refractories undergoing severe temperature variations, Journal of the European Ceramic Society. 36 (2016) 2329-2340. doi:10.1016/j.jeurceramsoc.2016.01.022.

[55] W. Sutherland, LII. The viscosity of gases and molecular force, The London, Edinburgh, and Dublin Philosophical Magazine and Journal of Science. 36 (1893) 507-531. doi:10.1080/14786449308620508.

[56] G. Barreto, P. Canhoto, M. Collares-Pereira, Three-dimensional modelling and analysis of solar radiation absorption in porous volumetric receivers, Applied Energy. 215 (2018) 602614. doi:10.1016/j.apenergy.2018.02.065.

[57] X. Chen, F. Wang, X. Yan, Z. Cheng, Y. Han, Z. Jie, Thermal and chemical analysis of methane dry reforming in a volumetric reactor under highly concentrated solar radiation, Solar Energy. 162 (2018) 187-195. doi:10.1016/j.solener.2018.01.032.

[58] M. Nakakura, K. Matsubara, S. Bellan, T. Kodama, Efficiency and heat loss analysis of honeycomb receiver varying air mass flow rate and beam width, International Journal of $\begin{array}{lllll}\text { Heat } & \text { and } & \text { (2019) } & \text { 1027-1040. }\end{array}$ doi:10.1016/j.ijheatmasstransfer.2019.03.153.

[59] M. Nakakura, S. Bellan, K. Matsubara, T. Kodama, Conjugate radiation-convectionconduction simulation of volumetric solar receivers with cut-back inlets, Solar Energy. 170 (2018) 606-617. doi:10.1016/j.solener.2018.06.006.

[60] C.K. Ho, A.R. Mahoney, A. Ambrosini, M. Bencomo, A. Hall, T.N. Lambert, Characterization of Pyromark 2500 paint for high-temperature solar receivers, Journal of Solar Energy Engineering. 136 (2014) 014502. doi:10.1115/1.4024031.

[61] M.H. Gray, R. Tirawat, K.A. Kessinger, P.F. Ndione, High temperature performance of highefficiency, multi-layer solar selective coatings for tower applications, Energy Procedia. 69 (2015) 398-404. doi:10.1016/j.egypro.2015.03.046. 

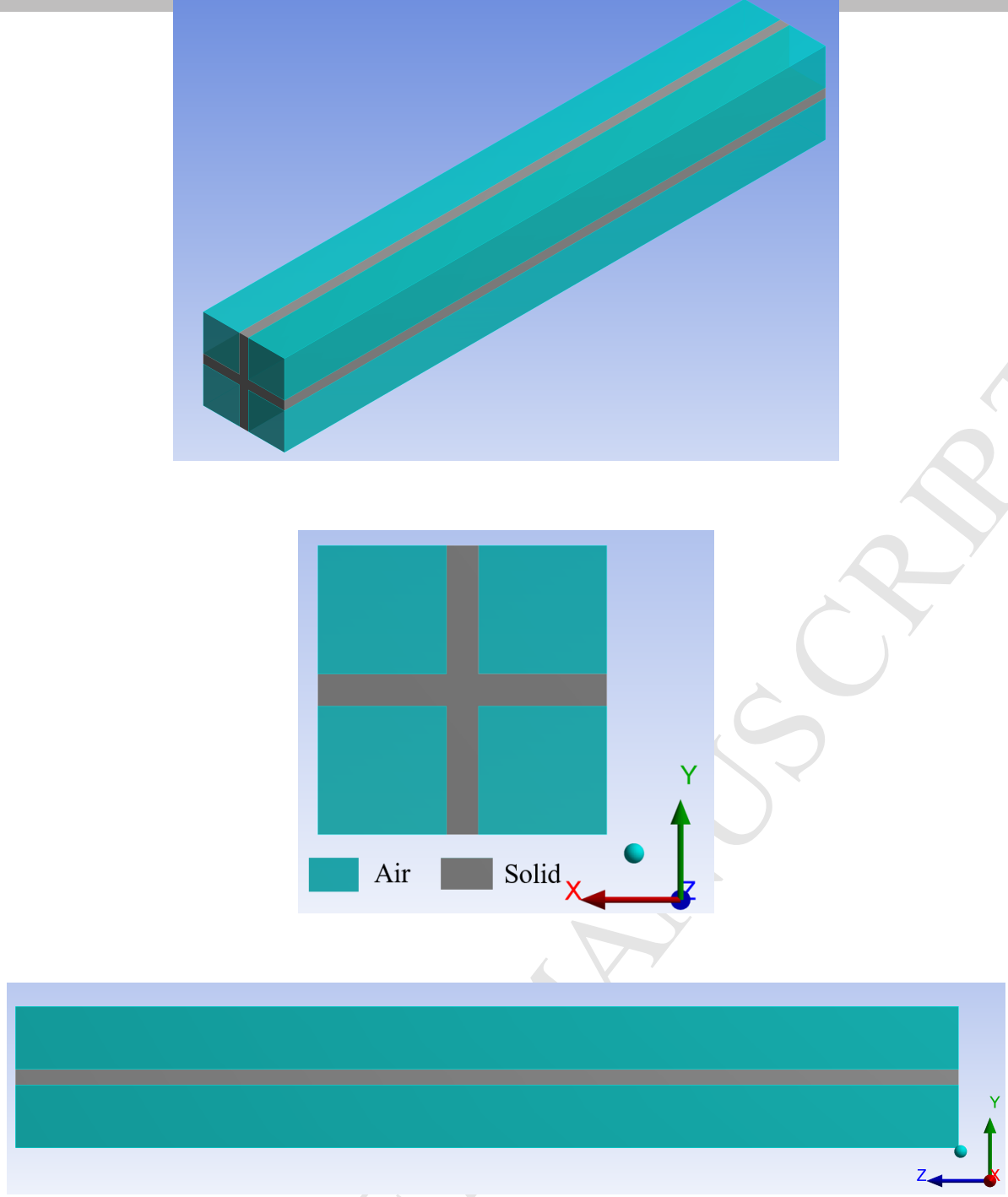

Figure 1: CFD solution domain 

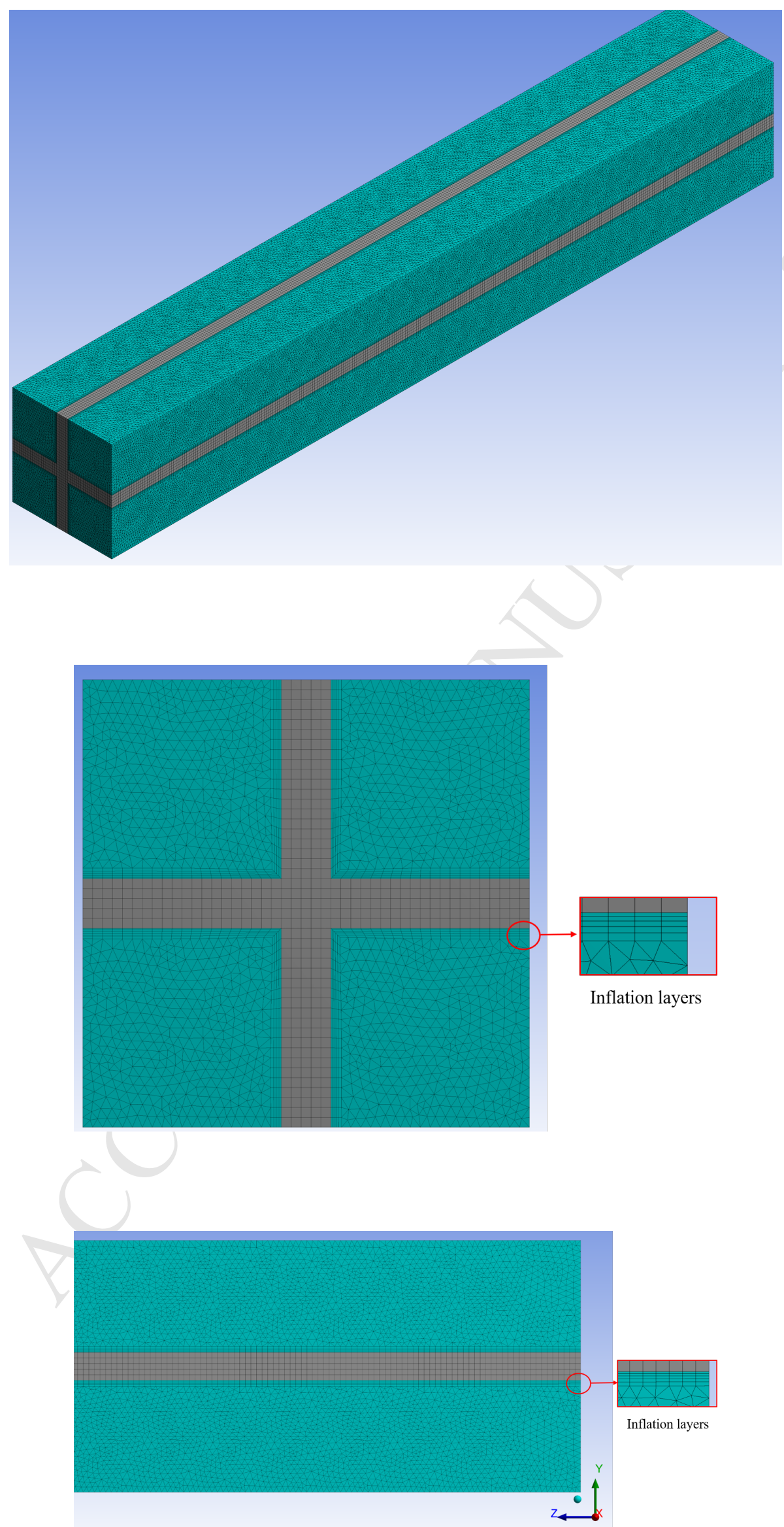

Figure 2: Numerical solution domain with generated mesh 
- Optical, CFD models for the analysis and design of volumetric solar receivers.

- Effects of absorber material and air flow rate on the performance are analyzed.

- A novel honeycomb receiver made of Alumina has been introduced.

- Coated alumina honeycomb absorbers show a favorable receiver performance. 